\title{
亚硝基化合物环加成反应的研究进展
}

\author{
李东君 ${ }^{a}$ 武彦芳 ${ }^{b}$ 常宏宏 ${ }^{a}$ 高文超 ${ }^{a}$ 魏文珑 $*, a$ 李 兴*, $a$ \\ ( ${ }^{a}$ 太原理工大学化学化工学院 太原 030024) \\ ( $b$ 大同大学化学与环境工程学院 大同 037008)
}

摘要 综述了近几年来亚硝基化合物与含各种不饱和键化合物环加成反应的研究进展, 主要包括[2+2]、[3+2]、[2+ $2+1] 、[3+3] 、[4+1]$ 和 $[4+2]$ 等环加成反应, 并对其发展方向进行了展望.

关键词 亚硝基; 环加成; 不饱和键

\section{Research Progress in the Cycloaddition Reactions of Nitroso Compounds}
Li, Dongjun ${ }^{a}$
Wu, Yanfang ${ }^{b}$
Chang, Honghong ${ }^{a}$
Gao, Wenchao ${ }^{a}$
Wei, Wenlong*,a
Li, Xing ${ }^{*, a}$
(College of Chemistry and Chemical Engineering, Taiyuan University of Technology, Taiyuan 030024)
(College of Chemistry and Environmental Engineering, Datong University, Datong 037008)

\begin{abstract}
The recent progress in the cycloaddition reactions of nitroso compounds with various compounds is reviewed, including [2+2], [3+2], $[2+2+1],[3+3],[4+1]$ and [4+2] cycloaddition reactions. Moreover, the prospects of future development are also discussed.
\end{abstract}

Keywords nitroso; cycloaddition; unsaturated bond

环加成反应 ${ }^{[1]}$ 是两个或多个不饱和分子通过结合生 成环状化合物, 并伴随有系统总键级数减少的化学反 应，它是合成单环及多环化合物的一种有效方法，该类 反应在发生过程中不消除小分子, 只生成 $\sigma$-键, 而且没 有 $\sigma$-键的断裂，因此原子利用率高; 常见的环加成反应 类型有 $[4+2] 、[2+2] 、[3+2] 、[2+2+1]$ 和 $[3+4]$ 等. 杂 环化合物骨架广泛存在于医药、农药、材料和天然产物 等分子结构中, 而环加成反应尤其是杂原子参与的环加 成反应则是构筑这类化合物最高效和直接的方法之一.

近二十年来, 亚硝基化合物作为含有 $\mathrm{N}$ 与 $\mathrm{O}$ 两种杂 原子的共轭体系已引起了国内外许多科研工作者的广 泛关注, 它们与含有各种不饱和键化合物发生的环加成 反应在合成噁嗪、异噁唑、吡咯烷和吲哚等多种杂环化 合物方面都具有很大的应用价值, 通过对环加成产物的 进一步修饰, 可得到多种具有生物活性和药用价值的衍 生物, 如氨基醇、氨基酸、内酰胺、生物碱和其它含氮
化合物. 本文将针对含有不同不饱和键的化合物对近年 来亚硝基化合物参与的环加成反应研究进展进行综述.

\section{1 亚硝基化合物以亚硝基作为 2 原子组分参与 的环加成反应}

\section{$1.1 \mathrm{C}=\mathrm{C}$ 双键参与的环加成反应}

\subsection{1 烯酮化合物参与的 $[2+2]$ 环加成反应}

2009 年, Fu 课题组 ${ }^{[2]}$ 报道了在平面手性 4-二甲氨基 吡啶(DMAP) 衍生物催化作用下, 以二氯甲烷为溶剂, $0{ }^{\circ} \mathrm{C}$ 条件下各种烯酮与邻三氟甲基亚硝基苯的环加成 反应(Eq. 1). 对烯酮底物进行的扩展表明多数反应都能 取得良好到优秀的收率和对映选择性，而当 $\mathrm{R}$ 为小位阻 甲基，芳基(Ar)对位为吸电子基团时，反应仅能取得中 等的收率和很差的对映选择性. 此外, 作者还对加成产 物进行了应用拓展, 通过开环反应, 此加成产物可以转 变成许多有价值的化合物, 如在 $\mathrm{LiAlH}_{4}$ 与锌粉、 $\mathrm{AcOH}$ 、

\footnotetext{
*E-mail: lixing@tyut.edu.cn

Received April 1, 2016; revised May 13, 2016; published online June 8, 2016.

Project supported by the Natural Science Foundation of Shanxi Province (Nos. 2012021007-2).

山西省自然科学基金(Nos. 2012021007-2)资助项目.
} 
$\mathrm{H}_{2} /(\mathrm{Pd} / \mathrm{C})$ 两个还原体系分别作用下开环可得到 1,2-二醇 和 $\alpha$-羟基羧酸.
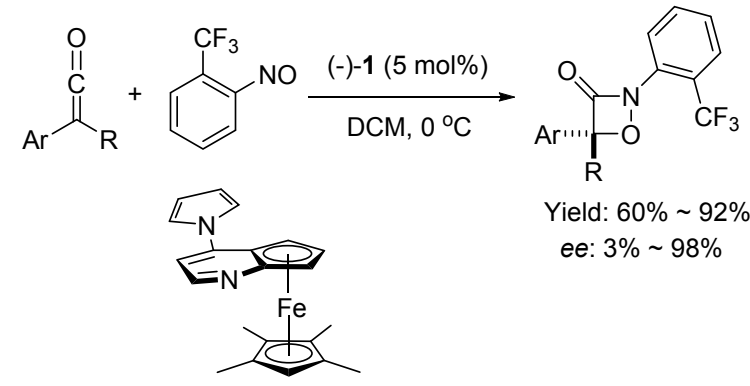

$(-)-1$

$\mathrm{R}=\mathrm{Me}, \mathrm{Et}, i-\mathrm{Pr}, i-\mathrm{Bu}$, cyclopentyl; $\mathrm{Ar}=\mathrm{Ph}, 2-\mathrm{MeC}_{6} \mathrm{H}_{4}, 4-\mathrm{MeC}_{6} \mathrm{H}_{4}$, 2- $\mathrm{MeOC}_{6} \mathrm{H}_{4}, 4-\mathrm{MeOC}_{6} \mathrm{H}_{4}, 2-\mathrm{BrC}_{6} \mathrm{H}_{4}, 4-\mathrm{ClC}_{6} \mathrm{H}_{4}$, 1-naphthyl, 3-thienyl

2010 年, Ye 课题组 ${ }^{[3]}$ 将有机手性催化剂氮杂环卡宾 (NHC)应用到芳基烯酮与 2-三氟甲基亚硝基苯的不对称 环加成反应中(Eq. 2). 该反应仍然以吸电子的邻三氟甲 基亚硝基苯为标准底物, 通过对反应条件优化篎选得出 催化剂 $\mathrm{NHC}$ 用量为 $10 \mathrm{~mol} \%$, THF 为最佳溶剂, 反应于 $-20{ }^{\circ} \mathrm{C}$ 下进行能取得最佳收率和对映选择性. 对于不 同的芳香基取代的烯酮广普性考察表明: 富电子和缺电 子官能团取代的芳香烯酮均可得到中等到良好的收率 和良好到优秀的对映选择性, 值得注意的是, 当脂肪取 代基( $\mathrm{R}$ )为小位阻甲基时, 反应仅能得到 35\%的收率和 $70 \%$ 的对映选择性.

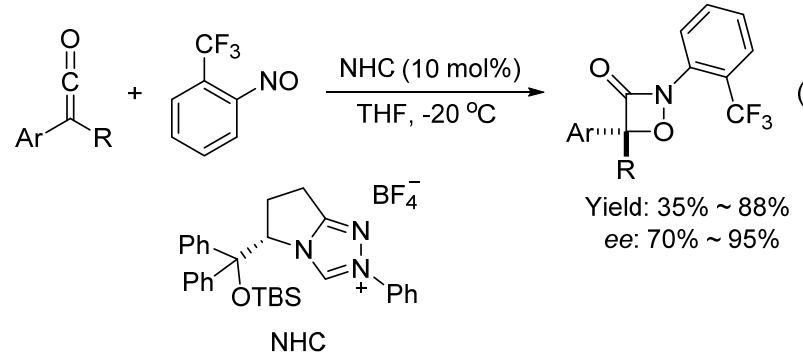

$\mathrm{R}=\mathrm{Me}, \mathrm{Et}, n-\mathrm{Pr}, n-\mathrm{Bu}, \mathrm{CH}_{2} \mathrm{CH}\left(\mathrm{CH}_{3}\right)_{2} ; \mathrm{Ar}=\mathrm{Ph}, 2-\mathrm{ClC}_{6} \mathrm{H}_{4}$, 4- $\mathrm{ClC}_{6} \mathrm{H}_{4}, 3-\mathrm{MeC}_{6} \mathrm{H}_{4} ; 4-\mathrm{MeC}_{6} \mathrm{H}_{4}, 4-\mathrm{MeOC}_{6} \mathrm{H}_{4}$, 1-naphthyl

2010 年, Studer 课题组 ${ }^{[4]}$ 报道了用 $\mathrm{Cu}(\mathrm{I})$ 作催化剂催 化烯酮与 2-亚硝基吡啶发生[2+2]环加成制备 2-(2-吡啶 基)-1,2-氧氮杂环丁烷-3-酮衍生物的反应(Eq. 3). 该反 应是以二氯甲烷作溶剂, $10 \mathrm{~mol} \%\left[\mathrm{Cu}(\mathrm{MeCN})_{4}\right] \mathrm{PF}_{6}$ 作催 化剂, $10 \mathrm{~mol} \%(R, P)$-Walphos- $\mathrm{CF}_{3}$ 作配体于 $-70{ }^{\circ} \mathrm{C}$ 条件 下进行的, 对烯酮底物进行扩展发现位阻效应对反应结 果的影响比较大, 当烯酮苯环上邻位有取代基时, 反应 的收率和选择性都大幅度降低, 其他多数底物都可取得 中等到良好的收率和良好到优秀的对映选择性. 此外, 作者还运用 DFT 计算方法对此[2+2]环加成反应的机理 进行了推测.

\subsection{2 烯丙基化合物参与的 $[3+2]$ 环加成反应}

2008 年, Connell 课题组 ${ }^{[5]}$ 报道了无催化剂条件下,

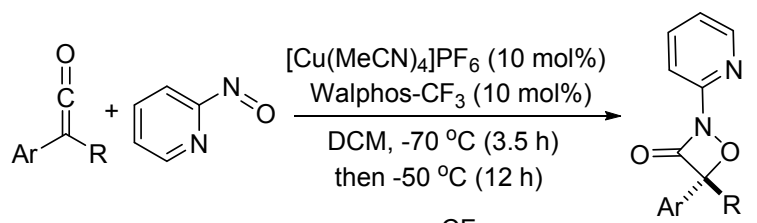

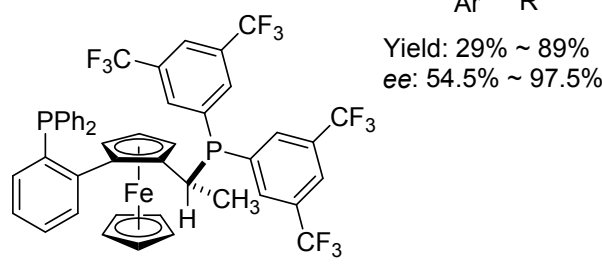

$(R, P)$-Walphos- $\mathrm{CF}_{3}$

$\mathrm{R}=\mathrm{Me}, \mathrm{Et}, i-\mathrm{Pr}, i-\mathrm{Bu}$, heteroaryl

$\mathrm{Ar}=2-\mathrm{MeC}_{6} \mathrm{H}_{4}, 3-\mathrm{MeC}_{6} \mathrm{H}_{4}, 4-\mathrm{MeC}_{6} \mathrm{H}_{4}, 2-\mathrm{FC}_{6} \mathrm{H}_{4}, 3-\mathrm{FC}_{6} \mathrm{H}_{4}$,

3- $\mathrm{MeOC}_{6} \mathrm{H}_{4}, 4-\mathrm{ClC}_{6} \mathrm{H}_{4}, 2$-naphthyl, 3-thienyl

芳香族亚硝基化合物与芳基烯在乙腈溶剂中于室温条 件下环加成制备异噁唑衍生物的反应(Scheme 1). 对芳 基烯广普性研究表明, 不管是带有吸电子基还是供电子 基的苯乙烯，反应取得的收率均低于 49\%，不含取代基 的苯乙烯取得最高收率为 49\%; 对芳香族亚硝基化合物 的扩展表明，当亚硝基苯苯环对位有吸电子基(Br)时， 对反应收率没有明显影响, 文中并未考察富电子芳香族 亚硝基化合物的反应情况. 此外, 作者还探究了 $82{ }^{\circ} \mathrm{C}$ 条件下环加成反应的情况, 研究结果表明, 当反应温度 升高后，除了得到二取代的异噁唑外，还得到了接近等 量的三取代异噁唑. 对反应机理研究表明 $\mathrm{C}=\mathrm{C}$ 双键的 断裂是反应的关键步骤.

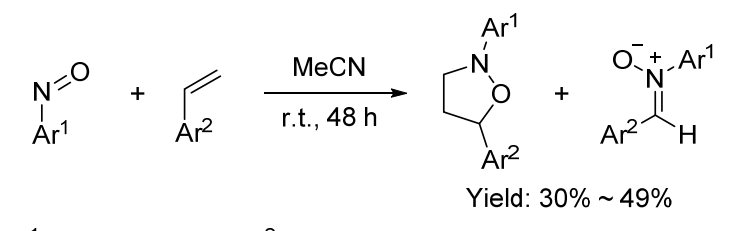

$\mathrm{Ar}^{1}=\mathrm{Ph}, 4-\mathrm{BrC}_{6} \mathrm{H}_{4} ; \mathrm{Ar}^{2}=\mathrm{Ph}, 2-\mathrm{MeC}_{6} \mathrm{H}_{4}, 4-\mathrm{MeC}_{6} \mathrm{H}_{4}, 3-\mathrm{ClC}_{6} \mathrm{H}_{4}$, 4-t- $-\mathrm{BuC}_{6} \mathrm{H}_{4}, 2-\mathrm{BrC}_{6} \mathrm{H}_{4}, 4-\mathrm{BrC}_{6} \mathrm{H}_{4}, 4-\mathrm{CF}_{3} \mathrm{C}_{6} \mathrm{H}_{4}$
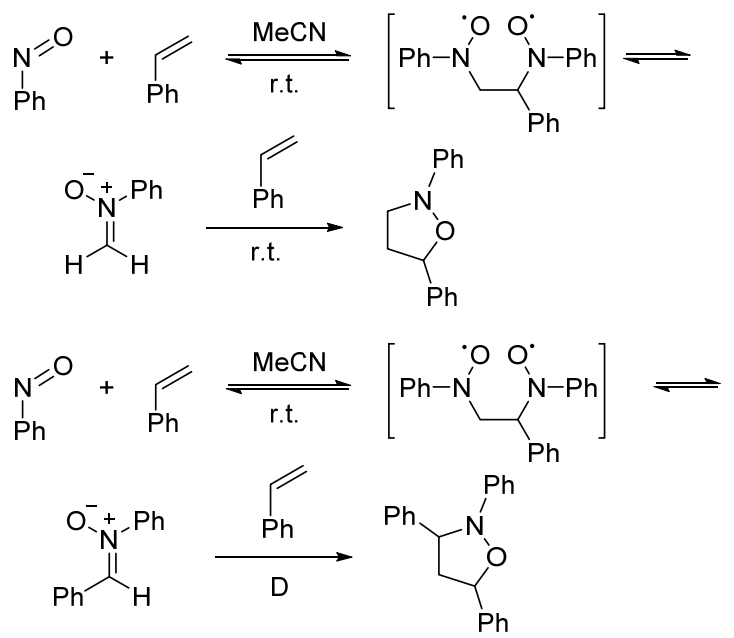

图式 1 芳基亚硝基化合物与芳基烯烃的 $[3+2]$ 环加成反应 Scheme $1[3+2]$ cycloadditions of nitrosoarenes with aromatic olefins 
2009 年, Zhong 课题组 ${ }^{[6]}$ 以氮杂环卡宾 $(\mathrm{NHC})$ 作催 化剂, 实现了 $\alpha, \beta$-不饱和烯醛与亚硝基芳香族化合物的 环加成反应(Eq. 4). 作者对反应机理进行了推测, 该反 应首先经历醛与芳香族亚硝基化合物的 $[3+2]$ 环加成过 程，随后经过分子内重排得到苯并七元环产物. 对不同 底物的扩展表明多数产物均取得了良好的收率, 特别是 䒬基、呋喃和噻吩等杂芳香 $\alpha, \beta$-不饱和烯醛也取得了良 好的收率; 但当苯环对位取代基为甲基时只取得了 $45 \%$ 的收率. 对亚硝基化合物的拓展发现当苯环上取代基为 吸电子的 $\mathrm{Cl}$ 和强供电子的甲氧基时均未得到理想的产 物.

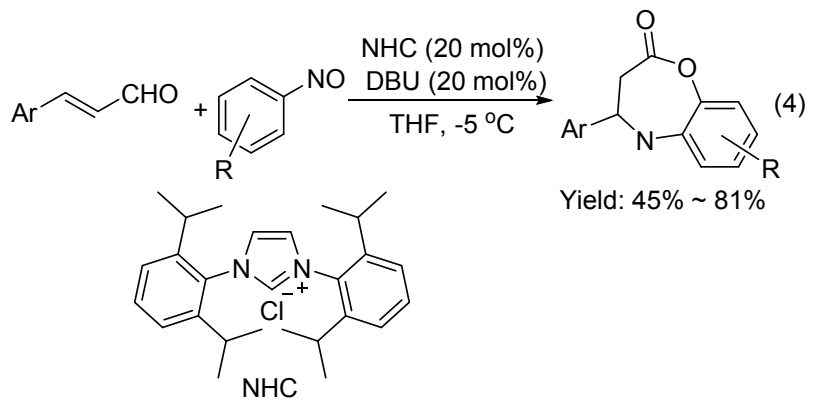

$\mathrm{R}=\mathrm{H}, 2-\mathrm{Me}, 4-\mathrm{Me} ; \mathrm{Ar}=\mathrm{Ph}, 4-\mathrm{MeC}_{6} \mathrm{H}_{4}, 4-\mathrm{ClC}_{6} \mathrm{H}_{4}, 2-\mathrm{BrC}_{6} \mathrm{H}_{4}$ 3- $\mathrm{BrC}_{6} \mathrm{H}_{4}, 4-\mathrm{BrC}_{6} \mathrm{H}_{4}, 4-\mathrm{CF}_{3} \mathrm{C}_{6} \mathrm{H}_{4}, 4-\mathrm{NO}_{2} \mathrm{C}_{6} \mathrm{H}_{4}$, 1-naphthyl, 2-furyl, 2-thienyl

2011 年, Studer 课题组 ${ }^{[7]}$ 报道了烯丙基锡类化合物 与 2-亚硝基吡啶的 $[3+2]$ 环加成反应(Eq. 5). 该反应以 $10 \mathrm{~mol} \%\left[\mathrm{Cu}(\mathrm{MeCN})_{4}\right] \mathrm{PF}_{6}$ 作催化剂, $10 \mathrm{~mol} \%$ Walphos$\mathrm{CF}_{3}{ }^{[4]}$ 作配体, 二氯甲烷作溶剂于 $-20{ }^{\circ} \mathrm{C}$ 下反应得到异 噁坐衍生物. 该反应具有中等到优秀的对映选择性和非 对映选择性以及 $29 \%$ 到 $99 \%$ 的收率. 通过对不同底物的 扩展发现位阻较大的顺式烯丙基加成产物依然保持优 秀的非对映选择性, 但对映选择性和收率较低. 此外, 作者在 $\left[\mathrm{Mo}(\mathrm{CO})_{6}\right] / \mathrm{NaBH}_{4}$ 的催化作用下, 实现了加成 产物 $\mathrm{N}-\mathrm{O}$ 键的断裂，得到了相应的氨基醇类化合物.
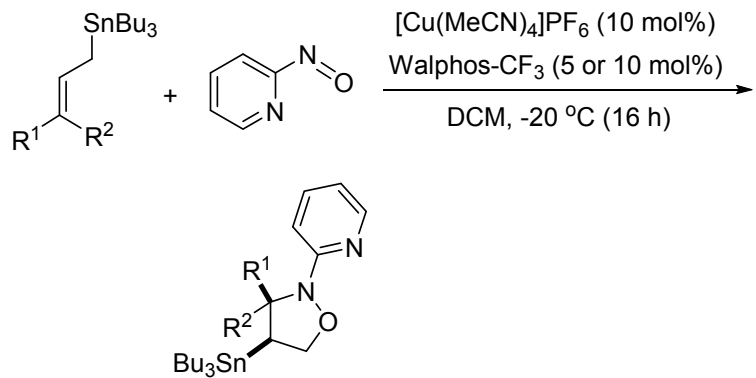

Yield: 29\% 99\%; dr. 67\% 99\%; ee: 45\% 99\%

$\mathrm{R}^{1}=\mathrm{H}, \mathrm{Me}, \mathrm{Et}, i-\mathrm{Pr}, t-\mathrm{Bu}, \mathrm{OMe}, n-\mathrm{Hex}, n-\mathrm{Pr}$;

$\mathrm{R}^{2}=\mathrm{H}, \mathrm{Me}, \mathrm{Et}, \mathrm{Ph}$

2013 年, Liu 课题组 ${ }^{[8]}$ 使用 $\left[\left\{\mathrm{P}(t-\mathrm{Bu})_{2}(o\right.\right.$-biphenyl $\left.)\right\}-$ $\mathrm{AuCl}] / \mathrm{AgSbF}_{6}$ 作催化剂在室温条件下完成了 1,5-烯炔和 亚硝基芳香族化合物的环加成反应(Eq. 6). 反应过程中 芳基烯炔首先与 $\mathrm{Au}^{+}$络合形成环丙烷结构中间体, 然后
亚硝基芳香族化合物与该中间体发生环加成反应，最后 经过一个氧化过程便得到目标产物. 对不同芳香烯炔底 物进行拓展表明加成产物都能得到良好的收率，而当 $\mathrm{X}$ 为甲氧基时，由于产生中间体的去质子化，只能得到烯 炔自环化产物. 炔基上取代基 $\mathrm{R}$ 的考察表明无论 $\mathrm{R}$ 是芳 香取代基还是脂肪族取代基加成产物均能取得良好的 收率. 在对烯基上取代基 $\mathrm{R}^{1}$ 和 $\mathrm{R}^{2}$ 的研究表明脂肪族取 代基均能取得良好的收率，而供电子芳香取代基只能取 得 63\%到 67\%的收率. 此外，作者对不同亚硝基芳香底 物也进行了考察, 发现富电子基取代的亚硝基苯有利于 加成反应的进行，反应收率最高可达到 $91 \%$.

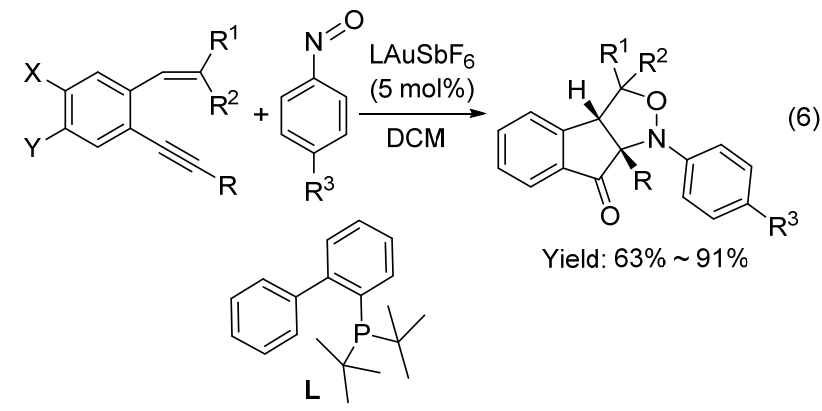

$\mathrm{X}=\mathrm{Y}=\mathrm{H}, \mathrm{Cl}, \mathrm{OCH}_{3} ; \mathrm{R}=\mathrm{Me}, n-\mathrm{Bu}, i-\mathrm{Pr}$, cyclopropyl, $\mathrm{Ph}$;

$\mathrm{R}^{1}=\mathrm{R}^{2}=\mathrm{H}, \mathrm{Me}, \mathrm{Et}, \mathrm{Ph}, \mathrm{MeOC}_{6} \mathrm{H}_{4} ; \mathrm{R}^{3}=\mathrm{OMe}, t-\mathrm{Bu}, \mathrm{Cl}, \mathrm{Br}, \mathrm{NO}_{2}$

2015 年, Xi 课题组 ${ }^{[9]}$ 报道了无催化剂条件下 2,6Diazasemibullvalene 与芳香族亚硝基化合物在甲苯溶剂 中制备 Aza-triquinacene 的反应(Scheme 2). 作者对反应 机理进行了推测: 首先亚硝基中的氮原子先进攻 2,6-Diazasemibullvalene 中的氮杂环丙烷部分得到开环 产物，接着该开环产物发生 $\mathrm{C}-\mathrm{C}$ 键断裂形成硝酮这一 关键中间体，最后硝酮中间体与烯键发生分子内 $[3+2]$ 环加成反应生成最终产物. 底物广普性考察表明亚硝基 苯作试剂时，与四种烯的反应可取得 $72 \%$ 到 $93 \%$ 的收 率; 而当用邻甲基亚硝基苯作试剂时，收率偏低，可取 得 60\% 到 83\%的收率. 此外, 加成产物在 $\mathrm{SmI}_{2}$ 催化作用 下发生 $\mathrm{N}-\mathrm{O}$ 键的断裂，得到了 $\Delta^{1}$-二吡咯啉衍生物，它 是构建许多生物分子的骨架结构.

2016 年, $\mathrm{Liu}$ 课题组 ${ }^{\left[{ }^{[0]}\right.}$ 报道了 $\mathrm{Cu}(\mathrm{I})$ 催化的 $N$-差㲇氨基 丙烯与亚硝基芳香族化合物的环加成反应(Eq. 7). 该反 应是以 $5 \mathrm{~mol} \%$ [( $\mathrm{IPr}) \mathrm{CuCl}][\mathrm{IPr}=1,3$-双 (二异丙基苯基) 咪唑-2-亚基]作催化剂, 甲苯作溶剂, 以 $\mathrm{O}_{2}(101 \mathrm{kPa})$ 作 氧化剂于室温条件下进行的. 作者首先考察了 $\mathrm{N}$ 上芳香 取代基对反应收率的影响，发现芳环上取代基的电子效 应对反应收率的影响较弱，反应均能取得中等左右的收 率 $(68 \% \sim 76 \%)$ 和优秀的非对映选择性 $(>25: 1)$; 烯键 上取代基 $\mathrm{R}$ 的考察表明，无论 $\mathrm{R}$ 是芳香取代基还是脂肪 取代基，反应都能取得中等左右的收率(60\% 76\%)和 优秀的非对映选择性 $(>25: 1)$; 对芳香族亚硝基化合 
<smiles>[R]C1=CC2([R1])N=C([R])CC2C1[R7]</smiles>

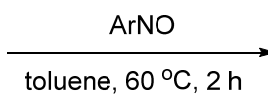

$\mathrm{R}^{1}=\mathrm{Me}, \mathrm{Bu}$

$\mathrm{R}^{2}=t-\mathrm{Bu}$, 3-methylpentane

(1) $\mathrm{Sml}_{2}$ (3.0 equiv.) THF, r.t., $6 \mathrm{~h}$

(2) $\mathrm{H}_{2} \mathrm{O}$

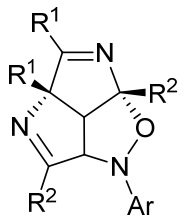

Yield: $60 \% \sim 93 \%$

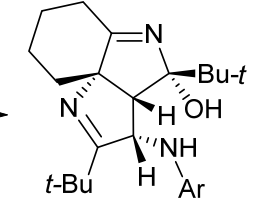

$\mathrm{Ar}=\mathrm{Ph}, 2-\mathrm{MeC}_{6} \mathrm{H}_{4}$ $\Delta^{1}$-bipyrrolines
图式 2 芳基亚硝基化合物与 2,6-diazasemibullvalenes 的[3+ 2]环加成反应

Scheme 2 Catalyst-free formal [4+2] cycloadditions of nitroso compounds with 1,3-butadienes

物的扩展表明，当芳环上取代基是供电子基团甲基时反 应收率稍低(61\%), 而当取代基是吸电子基团时反应收 率在 $80 \%$ 左右. 值得注意的是, 该加成产物在对甲基苯 磺酸的催化作用下能得到中等收率的喹啉氮氧化物.

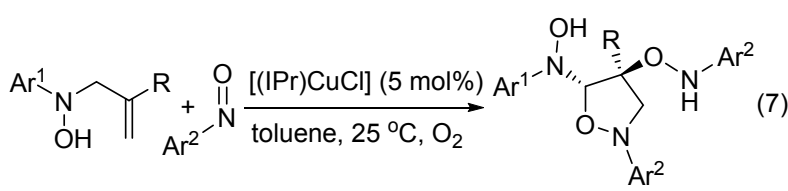

$\mathrm{R}=\mathrm{Me}, \mathrm{Et}$, isopentyl, $\mathrm{Ph}$

Yield: $54 \% \sim 80 \%$; $d r:>25: 1$

$\mathrm{Ar}^{1}=\mathrm{Ph}, 4-\mathrm{MeC}_{6} \mathrm{H}_{4}, 4-t-\mathrm{BuC}_{6} \mathrm{H}_{4}, 4-\mathrm{ClC}_{6} \mathrm{H}_{4}, 4-\mathrm{FC}_{6} \mathrm{H}_{4}$

$\mathrm{Ar}^{2}=\mathrm{Ph}, 4-\mathrm{MeC}_{6} \mathrm{H}_{4}, 4-\mathrm{ClC}_{6} \mathrm{H}_{4}, 4-\mathrm{BrC}_{6} \mathrm{H}_{4}$,

4- $\mathrm{NO}_{2} \mathrm{C}_{6} \mathrm{H}_{4}, 4-\mathrm{COOMeC}_{6} \mathrm{H}_{4}$

\subsubsection{1,3-丁二烯参与的 $[4+2]$ 环加成反应}

2000 年, Sanz-Tejedor 课题组 ${ }^{[11]}$ 成功实现了无催化 剂条件下手性 1-对甲苯亚硫酰基-1,3-戊二烯与亚硝基 甲酸苄酯发生环加成反应来制备高区域选择性二氢1,2-噁嗪衍生物 (Scheme 3). 通过对噁嗪的二羟基化和 氢解作用, 噁嗪可以高收率的转化成二羟基吡咯烷.

2004 年, Batey 课题组 ${ }^{[12]}$ 报道了 $N, N^{\prime}$-二叔丁氧羰 基- $N^{\prime \prime}$-羟基胍(亚硝基化合物前体)在 $\mathrm{Pr}_{4} \mathrm{NIO}_{4}$ 的氧化作 用下原位生成亚硝基化合物与二烯烃的环加成反应 (Scheme 4), 并通过对环加成产物的进一步处理实现了 多官能团化胍衍生物的制备. 作者对不对称二烯烃底物 进行了拓展，产物均取得了中等到良好的收率(60\% 86\%)和良好到优秀的区域选择性(81：19～98：2); 对 称二烯烃由于其对称性, 所以能得到一种产物, 且收率 在 $78 \%$ 到 $85 \%$ 之间.

2004 年, Yamamoto 课题组 ${ }^{[13]}$ 利用 $\left[\mathrm{Cu}(\mathrm{MeCN})_{4}\right] \mathrm{PF}_{6}$ 作催化剂, 在手性膦配体 $(S)$-SEGPHOS 的作用下实现 了取代的 2-亚硝基吡啶化合物与 $\mathrm{R}^{2}$ 取代的环己二烯的

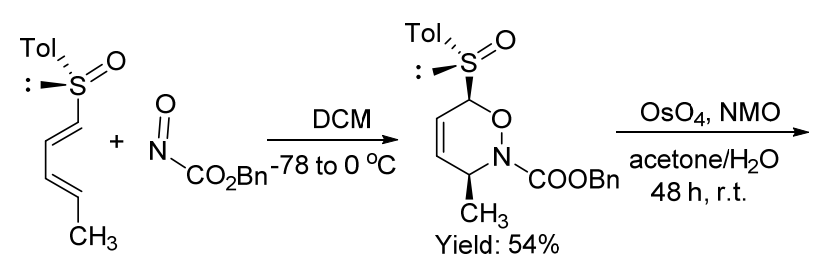

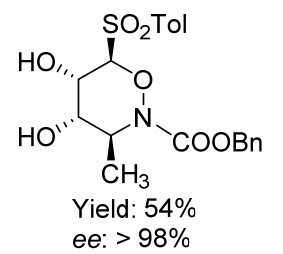

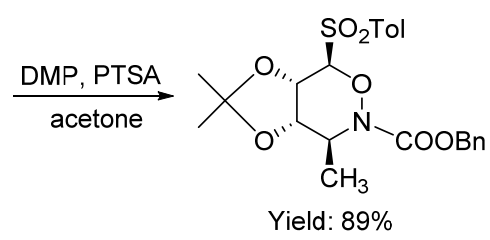<smiles>CCOC(=O)OCCOC(=O)OCc1ccccc1</smiles>

图式 3 芳基亚硝基化合物与 2,6-diazasemibullvalenes 的[3+ 2]环加成反应

Scheme 3 [3+2] cycloadditions of nitrosoarenes with 2,6-diazasemibullvalenes
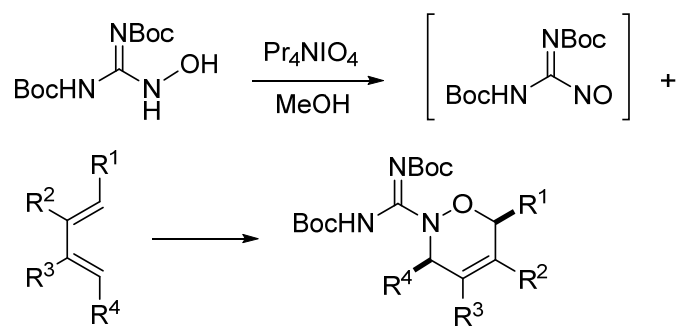

Yield: $60 \% \sim 86 \%$

ratio: $81: 19 \sim 98: 2$

$\mathrm{R}^{1}=\mathrm{H}, \mathrm{Me}, \mathrm{Et}, \mathrm{OMe}, t-\mathrm{Bu}, \mathrm{CH}_{2} \mathrm{OH} ; \mathrm{R}^{2}=\mathrm{R}^{3}=\mathrm{R}^{4}=\mathrm{H}, \mathrm{Me}$

图式 4 亚硝基榺类化合物参与的杂 DA 反应

Scheme 4 Hetero Diels-Alder reactions of nitrosoamidines

亚硝基 DA 环加成反应(Eq. 8). 对亚硝基底物广普性的 考察发现当 $\mathrm{R}$ 为甲基和乙基时，反应能取得优秀的收率 和良好的对映选择性，而当 $\mathrm{R}$ 为氢或大位阻的异丙基时 产物仍可取得优秀的收率，但对映选择性分别为 59\%和 77\%. 无论是苯基、甲基还是叔丁基硅基取代的环己二 烯反应均取得了优秀的收率和优秀的对映选择性.

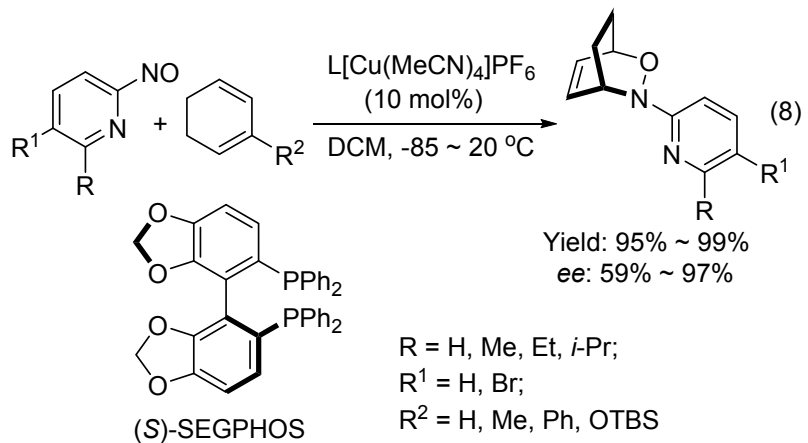


2005 年, Kouklovsky 课题组 ${ }^{[14]}$ 报道了 $\alpha$-醋酸基亚硝 基亲二烯体与二烯烃的环加成反应(Eq. 9). 作者在实验 过程中意外发现痕量的水对两种产物 $\mathbf{A}$ 和 $\mathbf{B}$ 的比例有 重要的影响, 通过对反应条件的优化篮选得出以水作溶 剂, 无催化剂条件下即可得到以环加成反应为主的产物 A. 通过对不同二烯烃底物的拓展表明多数烷基取代的 二烯烃底物均取得了中等到良好的收率和中等到良好 的区域选择性，而当 $\mathrm{R}^{3}$ 为芳基取代时，反应没有明显的 选择性.<smiles>CC(=O)OC1([N+](=O)[O-])COC(C)(C)OC1</smiles><smiles>[R1]C=C([R])C[R]</smiles>

(1) $\mathrm{H}_{2} \mathrm{O}$, r.t.

(2) $\mathrm{HCl}_{\mathrm{aq}}$

(3) $\mathrm{NaOH}, \mathrm{Boc}_{2} \mathrm{O}$<smiles>[R]C1=C([R])C([R])N(C(C)(C)C)OC1[R]</smiles>

A<smiles>CC(C)(C)OC(=O)NC1C=CC(O)CC1</smiles>

$$
\text { B }
$$

$\mathrm{R}^{1}=\mathrm{H}, \mathrm{Me}, \mathrm{CH}_{2} \mathrm{OH}, \mathrm{CH}_{2} \mathrm{OTBS} ; \mathrm{R}^{2}=\mathrm{H}, \mathrm{Me}$ dr. 50:50 98:2 $\quad \mathrm{R}^{3}=\mathrm{H}, \mathrm{Me}, \mathrm{Ph}, \mathrm{Ar} ; \mathrm{R}^{4}=\mathrm{H}, \mathrm{Me}$

2005 年, Yamamoto 课题组 ${ }^{[15]}$ 以 $(S)$-difluorophos 作 配体, 在 $\left[\mathrm{Cu}(\mathrm{MeCN})_{4}\right] \mathrm{PF}_{6}$ 的催化作用下报道了直链烯 烃与 2-亚硝基-6-甲基吡啶发生的不对称亚硝基 DA 环 加成反应(Eq. 10). 对二烯烃广普性研究表明所考察底 物都能得到单一的非对映异构体产物, 并且取得良好到 优秀的收率和对映选择性, 值得注意的是, 当底物采用 $\mathrm{R}^{2}$ 为乙烯基和苯乙烯基的三烯时，也得到了单一的非 对映选择性异构体产物, 收率达到 $84 \%$ 以上, 对映选择 性达到了 $85 \%$ 以上.<smiles>[R]C=CC(=C[R])O[AsH][I-]</smiles>

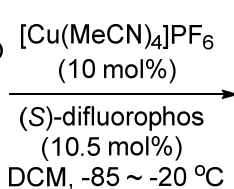<smiles></smiles>

(S)-difluorophos

$\mathrm{R}^{1}=$ alkyl; $\mathrm{R}^{2}=\mathrm{Me}$, cyclohexyl, vinyl, styrene, $\mathrm{Ph}, \mathrm{Ar}, 2$-furyl

2007 年, Studer 课题组 ${ }^{[16]}$ 使用 Walphos-CF 作配体 $^{[4]}$ 报道了取代的环已二烯与 2-亚硝基吡啶在 $[\mathrm{Cu}(\mathrm{Me}-$ $\left.\mathrm{CN})_{4}\right] \mathrm{PF}_{6}$ 催化作用下的不对称亚硝基 $\mathrm{DA}$ 环加成反应 (Eq. 11). 该研究首先选择高手性二烯烃 $[\mathrm{R}=(S)$ CHPhOTBDPS (TBDPS = tert-butyldiphenylsilyl), 98\%

$e e$ 与 2-亚硝基吡啶做模板反应，对一系列配体进行了 篮选, 结果是反应在配体 Walphos- $\mathrm{CF}_{3}$ 与路易斯酸 $\left[\mathrm{Cu}(\mathrm{MeCN})_{4}\right] \mathrm{PF}_{6}$ 催化作用下得到了八种异构体中的两 种主要异构体产物 $\mathbf{C}$ 和 $\mathbf{D}$. 经过对不同底物的拓展，产 物 C 和 D 分别取得了 39\%到 48\%的收率和 42\%到 52\% 的收率，它们分别都取得了优秀的对映选择性和良好到 优秀的对映选择性. 2009 年, 该课题组 ${ }^{[17]}$ 在同样的条件 下对取代环己二烯与 2-亚硝基吡啶的不对称亚硝基 DA 环加成反应进行了研究(Eq. 12). 对不同 2 位取代的环己 二烯底物进行了拓展，当 $\mathrm{R}$ 为 OTf 取代时得到了两种异 构体收率分别为 $33 \%$ 和 $66 \%$ ，当 $\mathrm{R}$ 为其他取代基时反应 均得到了单一产物，且收率在 $97 \%$ 以上，对映选择性在 90\%左右. 值得一提的是，杂环二烯烃 $N$-甲氧羰基吡啶 也取得了 $94 \%$ 的收率和 $96 \%$ 的对映选择性. 借助此加成 反应, 该课题组成功合成了天然产物 $(-)$-conduramine A-1.
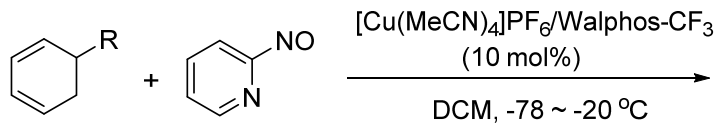<smiles>[R]C1C2C=CC(C2)N1P</smiles>

C

Yield: $39 \% \sim 48 \%$ ee: $95 \% \sim 99 \%$

$\mathrm{R}=\mathrm{CH}_{2} \mathrm{OAc}, \mathrm{CMe}_{2} \mathrm{OTMS}, \mathrm{CHOTBDPS}, \mathrm{CH}_{2} \mathrm{Ph}, \mathrm{Ph}$
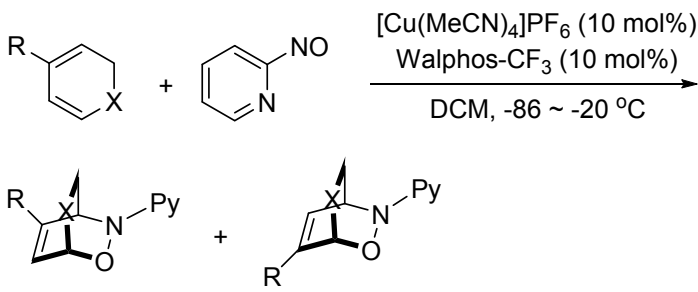

Yield: $33 \% \sim 99 \% \quad$ Yield: $<2 \% \sim 66 \%$ ee: $81 \% \sim 93 \% \quad$ ee: $98 \%$ $\mathrm{R}=\mathrm{H}, n-\mathrm{Bu}$, OTBS, Ph, OTf; $\mathrm{X}=\mathrm{CH}_{2}$, NMoc<smiles>CC(=O)OC1C=CC(N)C(OC(C)=O)C1OC(C)=O</smiles>

(-)-Conduramine A-1

2008 年, Marchand-Brynaert 课题组 ${ }^{[18]}$ 在微波条件下 实现了二乙基-1-膦酰基-1,3-丁二烯与邻甲基亚硝基苯 的 $[4+2]$ 环加成反应(Scheme 5). 作者对加成产物进行 了应用拓展, 产物在醋酸和 $\mathrm{Zn}$ 粉作用下, 再经过脱水 关环可生成吡咯烷衍生物, 这是一条合成取代吡咯烷的 新路线. 


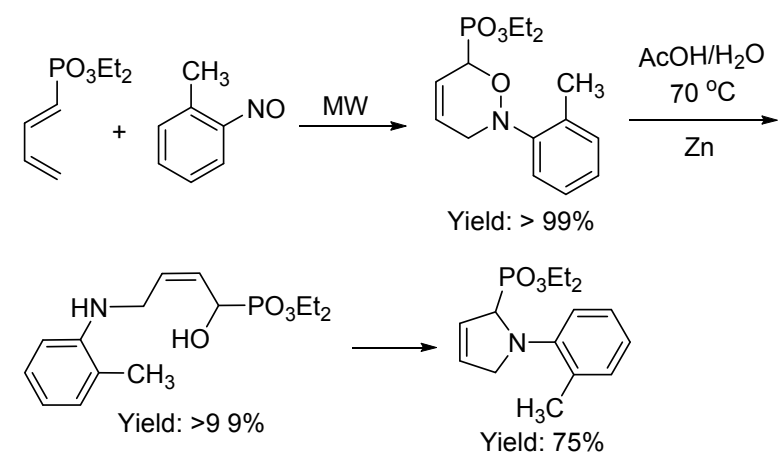

图式 5 微波条件下亚硝基化合物与 1,3-丁二烯的 [4+2]环加 成反应

Scheme 5 [4+2] cycloadditions of nitroso compounds with 1,3-butadienes under microwave activation

2008 年, Studer 课题组 ${ }^{[19]}$ 利用 2-亚硝基吡啶与双烯 化合物的环加成反应实现了 (+)-反式-二氢水仙环素 $[(+)$-trans-Dihydronarciclasine $]$ 的全合成(Eq. 13). 铜配 合物催化剂 $\left(\left[\mathrm{Cu}(\mathrm{MeCN})_{4}\right] \mathrm{PF}_{6}\right)$ 催化的高对映选择性亚硝 基 DA 反应是合成水仙环素的关键步骤, 含不同取代基 的二烯烃底物, 均有两种异构体 $\mathbf{E}$ 和 $\mathbf{F}$ 的产生, 且都可 取得良好到优秀的对映选择性，但收率较差都不足 $60 \%$ 和 $73 \%$. 当 $\mathrm{R}^{1}$ 为 $\mathrm{CH}_{2} \mathrm{OTBs}$ 或者 $\mathrm{CONMe}_{2}$ 时产物 $\mathbf{E}$ 对映 选择性有所降低, 仅为 $70 \%$.<smiles></smiles><smiles>[R2]Oc1c(C2CC3OC4CC2ON43)cc2c(c1[R])OCO2</smiles>

$\mathrm{E}$

Yield: $48 \% \sim 55 \%$ ee: $70 \% \sim 99 \%$<smiles>[R2]Oc1c(C2C3C=CC(O3)N2[R7])cc2c(c1[R])OCO2</smiles>

$F$

Yield: $31 \% \sim 51 \%$ ee: $92 \% \sim 98 \%$
$\mathrm{R}^{1}=\mathrm{H}, \mathrm{COOMe}, \mathrm{CH}_{2} \mathrm{OH}, \mathrm{CH}_{2} \mathrm{OTBS}, \mathrm{CONMe}_{2} ; \mathrm{R}^{2}=\mathrm{Me}$, TBS

2009 年, Miller 课题组 ${ }^{[20]}$ 报道了麦角甾醇与亚硝基 化合物发生的亚硝基 DA 反应, 并通过对其环加成产物 $\mathrm{N}-\mathrm{O}$ 键的还原消除成功合成了甾醇类化合物(Scheme 6). 环加成反应广普性考察表明, 当 $\mathrm{R}^{1}$ 为苯甲酰基时反 应取得较差的收率 $(12 \%)$, 而其它考察的底物均能取得 良好到优秀的收率. 随后, 作者借助钠录齐试剂成功地 实现了加成产物 $\mathrm{N}-\mathrm{O}$ 键的断裂来制备甾醇类衍生物.

2010 年, Marchand-Brynaert 课题组 ${ }^{[21]}$ 在微波或加热 条件下考察了膦酰基丁二烯与各类亚硝基化合物的 $[4+2]$ 环加成反应(Scheme 7). 反应的广普性考察表明, 多数底物均取得了良好到优秀的收率; 脂肪族亚硝基化 合物也能很好地参与反应, 取得 $56 \%$ 到 $84 \%$ 的收率. 此

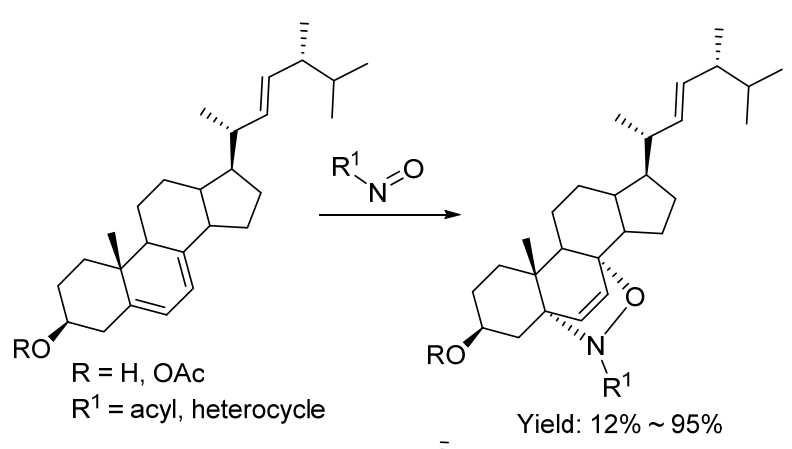<smiles>[R]N[C@]12C=C[C@@]3(O)C4CC[C@H]([C@H](C)/C=C/[C@H](C)C(C)C)[C@H]4CC[C@H]3[C@@]1(C)CC[C@@H]([R6])C2</smiles>

图式 6 麦角甾醇参与的亚硝基 DA 反应

Scheme 6 Nitroso Diels-Alder reactions of ergosterols

外, 环加成产物通过 $\mathrm{N}-\mathrm{O}$ 键的断裂可得到氨基醇类开 环产物，在碱性条件下，此开环产物又可以发生关环反 应得到多取代的环氧乙烷.
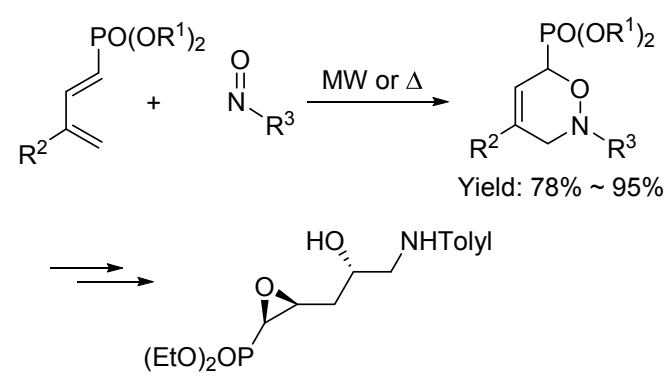

$\mathrm{R}^{1}=\mathrm{Et}, \mathrm{Bn} ; \mathrm{R}^{2}=\mathrm{H}$, TBDMSO; $\mathrm{R}^{3}=$ Tolyl, Ac, Bz, COBn, COO-t-Bu

图式 7 亚硝基化合物与 1,3-丁二烯的 [4+2]环加成反应 Scheme 7 [4+2] cycloadditions of nitroso compounds with 1,3-butadienes

2010 年, Stevens 课题组 ${ }^{[22]}$ 研究了微流促进条件下 着弪胺衍生物在 $\mathrm{NaIO}_{4}$ 氧化作用下变成亚硝基化合物, 然 后与二烯烃发生环加成反应(Scheme 8). 对不同底物的 拓展表明, 多数脂肪族羟胺均取得了中等到良好的收 率，而芳香族羟胺收率相对较好，在 75\%到 $96 \%$ 之间， 该反应体系不需要任何催化剂和添加剂.

2010 年, Miller 课题组 ${ }^{[23]}$ 报道了利用柱晶白霉素 (leucomycin)作为二烯烃与亚硝基化合物发生 DA 环加 成反应来制备一系列 10,13-二取代的十六元环内酯衍生 物(Eq. 14). 对不同亚硝基底物的拓展发现，脂肪族亚硝 基化合物和亚硝基苯均不适用于此反应，其他杂芳香基 


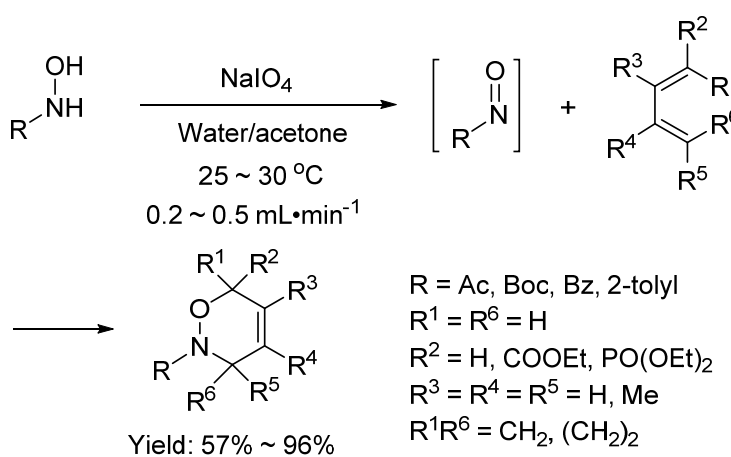

图式 8 微流条件下亚硝基亲二烯体参与的杂 DA 反应 Scheme 8 Straightforward hetero Diels-Alder reactions of nitroso dienophiles by microreactor technology

亚硝基化合物取得了 60\%到 91\%的收率，而 2-亚硝基嘧 啶由于稳定性较差, 仅取得了 13\%的收率, 硝基取代的 亚硝基吡啶也仅能取得 26\%的收率. 对柱晶白霉素底物 的考察发现, $\mathrm{R}^{1}$ 取代基对收率没有明显的影响. 值得注 意的是, 这些大环内酯衍生物大多都展现出中等的抗癌 性、细胞增生活性和抗癌活性.

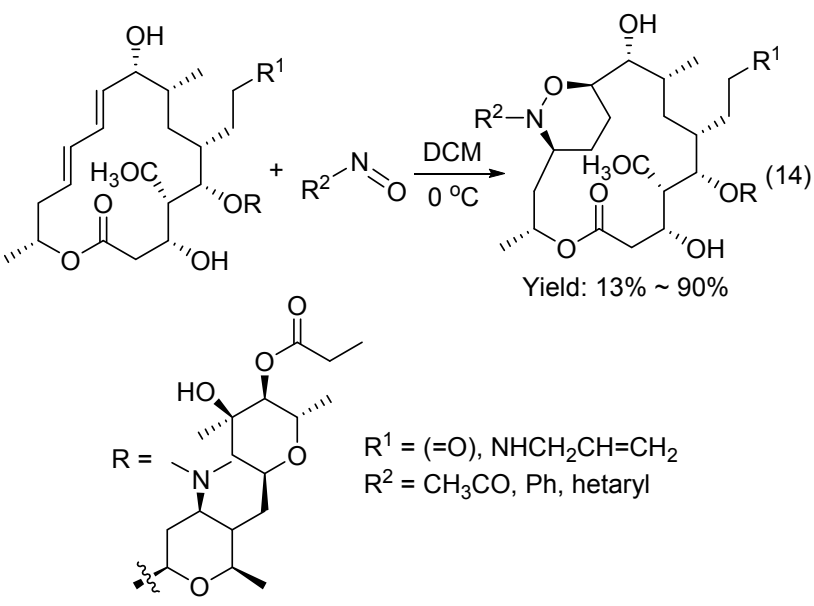

2011 年, Whiting 课题组 ${ }^{[24]}$ 报道了以 $10 \mathrm{~mol} \% \mathrm{CuCl}_{2}$ 作催化剂, 2-乙基-2-噁唑啉作配体, 氧气环境下氧化差弪 肜酸原位生成酰基亚硝基化合物, 再与二烯烃发生亚硝 基 DA 环加成反应(Scheme 9), 该体系相比之前的氧化 体系更加绿色温和 ${ }^{[25,26]}$. 对不同二烯烃底物广普性的考 察表明, 多数底物都能取得良好到优秀的收率 $73 \%$ 99\%). 到当时为止, 尽管关于 $\mathrm{Cu}(\mathrm{II})$ 催化的有氧氧化已 经有文献报道，但这是关于原位生成酰基亚硝基化合物 的第一例应用报道.

2012 年, Read de Alaniz 课题组 ${ }^{[27]}$ 报道了利用 20 $\mathrm{mol} \% \mathrm{CuCl}$ 作催化剂, $5 \mathrm{~mol} \%$ 吡啶(Pyr)作配体, $N$-取代 的羟胺在空气氧化下先生成亚硝基化合物, 然后再与二 烯烃发生环加成反应(Scheme 10). 作者对不同底物的 广普性进行了考察，除乙酰基亚硝基化合物取得 58\%的 收率之外, 其它亚硝基化合物(如甲酰亚硝基化合物、亚

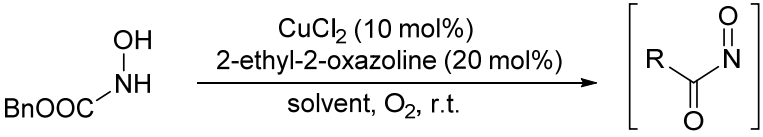

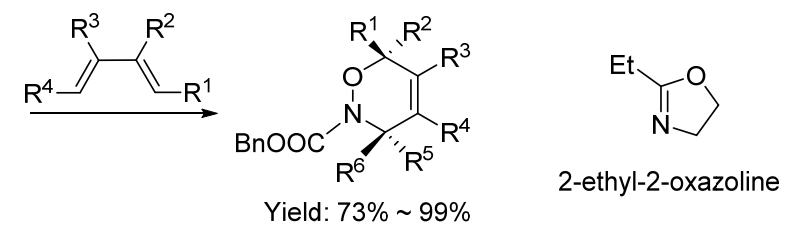

$\mathrm{R}^{1}=\mathrm{R}^{4}=\mathrm{H}, \mathrm{Me}, \mathrm{Ph} ; \mathrm{R}^{2}=\mathrm{R}^{3}=\mathrm{H}, \mathrm{Me} ; \mathrm{R}^{1} \mathrm{R}^{4}=\mathrm{CH}_{2},\left(\mathrm{CH}_{2}\right)_{2}$

图式 $9 \mathrm{CuCl}_{2}$ 催化下亚硝基化合物与 1,3-丁二烯的 $[4+2]$ 环 加成反应

Scheme $9 \mathrm{CuCl}_{2}$-catalyzed $[4+2]$ cycloadditions of nitroso compounds with 1,3-butadienes

硝基甲酰胺、亚胺亚硝基化合物和芳香族亚硝基化合 物)均能取得良好到优秀的收率; 对二烯烃底物的考察 发现，2,3-二甲基-1,3-丁二烯和 2-甲基-1,3-丁二烯底物 仅能取得 $71 \%$ 和 $43 \%$ 的收率，其它二烯烃底物能较好地 参与反应，产物收率在 $80 \%$ 到 $99 \%$ 之间; 对体系副反应 的研究表明，低活性的烯烃更容易发生副反应. 这又是 一例有氧氧化原位生成亚硝基化合物的报道.
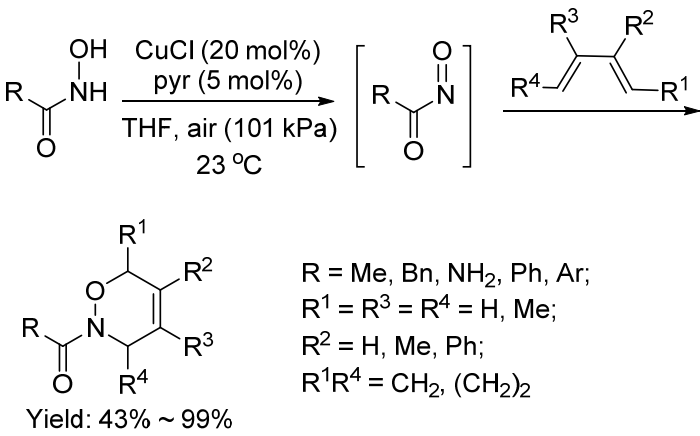

图式 $10 \mathrm{CuCl}$ 催化下亚硝基化合物与 1,3-丁二烯的[4+2]环 加成反应

Scheme 10 CuCl-catalyzed [4+2] cycloadditions of nitroso compounds with 1,3-butadienes

2012 年, Mahajan 课题组 ${ }^{[28]}$ 以反式-3-丁间二烯基-2氮杂环丁酮(trans-3-butadienyl-2-azetidinone)和亚硝基 苯的反应作模板反应对其环加成产物的区域选择性和 非对映选择性进行了研究(Eqs. 15，16). 对底物广普性 研究表明, 反式氮杂环丁酮只得到一种加成产物, 且都 得到了良好到优秀的收率( $80 \%$ \% $90 \%)$; 而对顺式氮杂 环丁酮的考察中发现，多数底物参与反应都有两种异构 体 $\mathbf{G}$ 和 $\mathbf{H}$ 产生，其比例接近 2：1，且总收率在 75\%到 $87 \%$ 之间.

2013 年, Pineschi 课题组 ${ }^{[29]}$ 报道了 $\mathrm{CuCl}$ 催化作用下 氮杂环己二烯与亚硝基苯经亚硝基 DA 反应制备吡咯衍 生物的反应(Scheme 11)，该反应经历了加成产物 [A]的 
<smiles>[R]c1ccc([C@H]2[C@H](/C=C/C=C)C(=O)N2c2ccc([R])cc2)cc1</smiles>

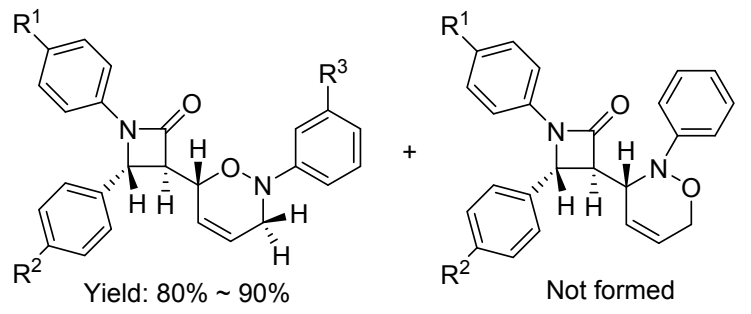

$\mathrm{R}^{1}=\mathrm{H}, \mathrm{Me}, \mathrm{Cl} ; \mathrm{R}^{2}=\mathrm{H}, \mathrm{OMe}, \mathrm{Cl} ; \mathrm{R}^{3}=\mathrm{H}, \mathrm{Me}$
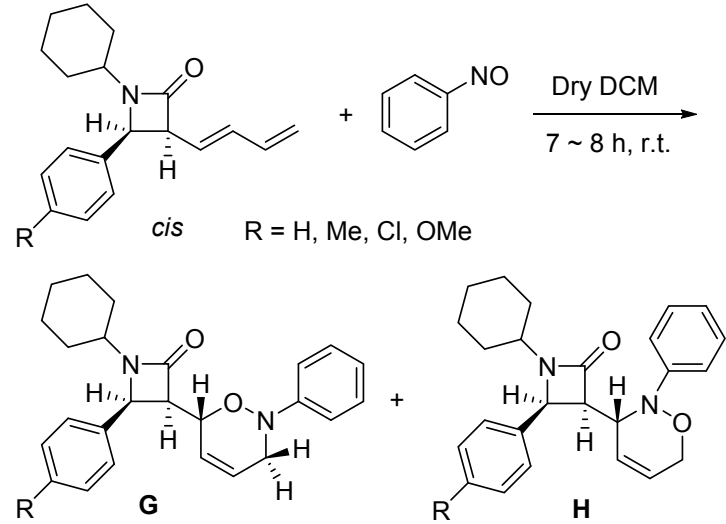

Yield: $75 \% \sim 87 \%$; ratio: $1.8: 1 \sim 2.2: 1$

$\mathrm{N}-\mathrm{O}$ 键断裂和六元环开环重排两个过程. 作者对含有 不同保护基和不同取代基的二烯烃底物进行了考察, 反 应结果表明: 所有底物都取得了不足 $72 \%$ 的收率, 而当 保护基为对甲苯磺酰基和苄氧基时, 反应活性大幅降 低，反应收率也仅在 $20 \%$ 左右.

$$
\begin{aligned}
& \text { R= H, Me, Ph. } \mathrm{CH}_{2} \mathrm{COOCH}_{3}, \mathrm{C}_{6} \mathrm{H}_{13} \\
& \text { Yield: } 25 \% \sim 72 \%
\end{aligned}
$$

图式 $11 \mathrm{CuCl}$ 催化下亚硝基苯与二氢吡啶的[4+2]环加成反 应

Scheme 11 CuCl-catalyzed [4+2] cycloadditions of nitrosobenzene with 1,2-dihydropyridines

2014 年, Read de Alaniz 课题组 ${ }^{[30]}$ 利用聚乙二醇羟 肟酸与聚苯乙烯环戊二烯作原料将亚硝基 HDA 反应应 用于高分子的合成中(Eq. 17). 该反应首先经过羟肜酸 氧化原位生成亚硝基化合物, 然后再与二烯发生环加成
反应. 通过对反应条件的进一步探究，该课题组实现了 无催化剂条件下通过亚硝基环加成反应制备嵌段共聚 物的方法, 取得了令人满意的效果.<smiles>COCCOCCOC(=O)N[OH2+]</smiles><smiles>CCOC(=O)C(C)(C)CC(C1=CC=CC1)c1ccccc1</smiles>

$\mathrm{CuCl}(20 \mathrm{~mol} \%)$, pyr (5 mol\%) THF, air, r.t<smiles>CCOCCC1C2C=CC1(C(CCC(=O)OCC)c1ccccc1)N(C(=O)OCCOCCOC)O2</smiles>

2015 年, Whiting 课题组 ${ }^{[31]}$ 报道了无催化剂条件下 1-硼酸频哪醇酯二烯与芳香族亚硝基化合物发生环加 成反应生成吡咯衍生物的反应(Scheme 12). 当使用甲 醇作溶剂时，通过对不同底物的拓展，大多芳香族亚硝 基化合物都能取得 57\%到 77\% 的收率; 所考察的二烯烃 当端烯为环烯 $R^{2} R^{3}=\left(\mathrm{CH}_{2}\right)_{4}$ 或者 $\mathrm{R}^{1}$ 为环己基时，反应 分别只能取得 $17 \%$ 和 34\% 的收率. 由于在反应过程中并 未检测到 $[4+2]$ 环加成产物啞嗪，接下来作者把二烯烃 端基取代基硼酸频哪醇酯(Bpin)改为喼酸二乙酸胺酯对 反应进行了详细的考察, 研究表明噁嗪是生成吡咯过程 的关键中间体。紧接着作者以 $(N$-甲基亚氨基乙酸)-硼 二烯作标准二烯烃底物在乙酸乙酯溶剂中成功得到了 $[4+2]$ 环加成产物噁嗪，通过对不同亚硝基化合物拓展， 所考察底物均取得了中等左右的收率，反应结果表明吸 电子基取代的亚硝基苯收率较高; 所考察的二烯烃也取 得了中等左右的收率，而当烯烃 C4 位上有苯基取代时， 反应可以得到两种啞嗪产物，尽管可取得 $89 \%$ 的总收 率, 但选择性较差.
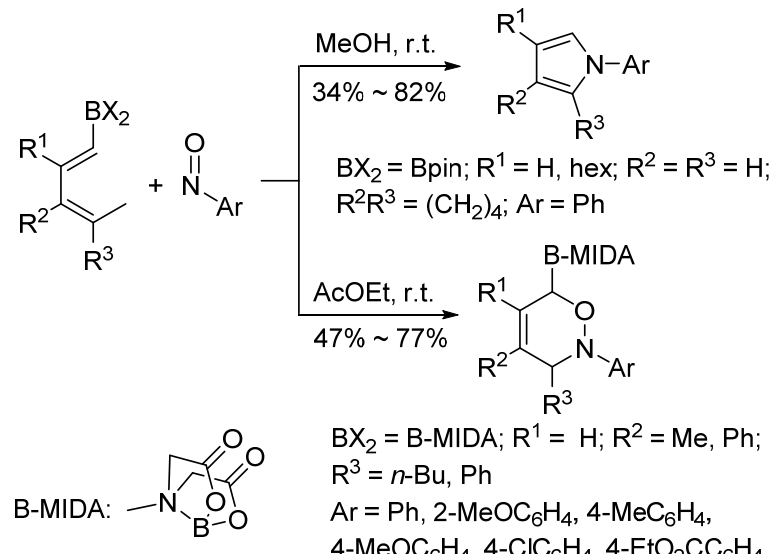

$\mathrm{BX}_{2}=\mathrm{B}-\mathrm{MIDA} ; \mathrm{R}^{1}=\mathrm{H} ; \mathrm{R}^{2}=\mathrm{Me}, \mathrm{Ph}$

$\mathrm{R}^{3}=n-\mathrm{Bu}, \mathrm{Ph}$

$\mathrm{Ar}=\mathrm{Ph}, 2-\mathrm{MeOC}_{6} \mathrm{H}_{4}, 4-\mathrm{MeC}_{6} \mathrm{H}_{4}$ 4- $\mathrm{MeOC}_{6} \mathrm{H}_{4}, 4-\mathrm{ClC}_{6} \mathrm{H}_{4}, 4-\mathrm{EtO}_{2} \mathrm{CC}_{6} \mathrm{H}_{4}$

图式 12 1-嗍基二烯与亚硝基芳香族化合物的环加成反应 Scheme 12 Cycloadditions of 1 borodienes with nitrosoarene compounds 
2015 年, Whiting 等 ${ }^{[32]}$ 从实验和理论计算两方面出 发，系统考察了羟弜酸在氧化作用下原位生成亚硝基化 合物, 紧接着与二烯烃的环加成反应(Scheme 13). 通过 对 $\mathrm{NaIO}_{4} / \mathrm{MeOH} 、 \mathrm{CuCl}_{2} / \mathrm{MeOH}$ 和 $\mathrm{CuCl}_{2} /$ Toluene 氧化体 系的比较发现, 环加成反应在 $\mathrm{CuCl}_{2} / \mathrm{MeOH}$ 体系能有效 地进行，且该体系仅适用于苯基与羰基之间存在杂原子 的差肟酸. 对不同烯烃底物的拓展表明当 $\mathrm{X}$ 为 $\mathrm{O}$ 时, 多 数反应都能取得优秀的收率, 而当 $\mathrm{X}$ 为 $\mathrm{N}$ 时, 反应可取 得 30\%到 $97 \%$ 的收率.
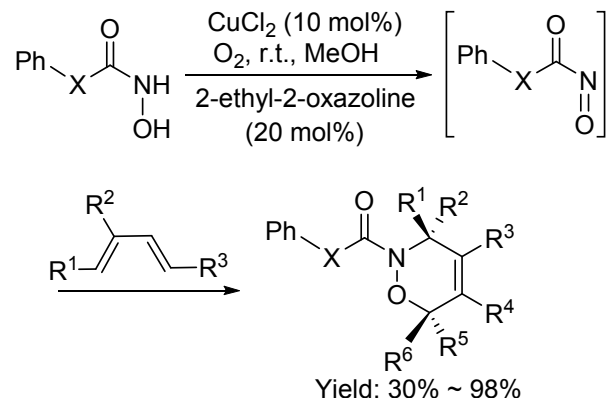

$\mathrm{X}=\mathrm{O}, \mathrm{NH} ; \mathrm{R}^{1}=\mathrm{H}, \mathrm{Me}, \mathrm{Ph}, \mathrm{CH}_{2} \mathrm{OH} ; \mathrm{R}^{2}=\mathrm{H}, \mathrm{Me} ; \mathrm{R}^{3}=\mathrm{Me}, \mathrm{Ph}$

图式 13 1,3-丁二烯与酰基亚硝基化合物的环加成反应 Scheme 13 Cycloadditions of 1,3-butadienes with acyl nitroso compounds

2015 年, Masson 课题组 ${ }^{[33]}$ 发现手性膦酸试剂 (TRIR)能够有效地催化氨基甲酸二烯与芳香族亚硝基 化合物发生的亚硝基环加成反应(Eq. 18). 该反应是在 - $50{ }^{\circ} \mathrm{C}$ 下, 甲苯作溶剂, 以 $5 \mathrm{~mol} \%(S)-3,3$ '二 $(2,4,6-$ 三 异丙基苯基)-联䒺酚膦酸(TRIR)作催化剂条件下进行 的. 通过对不同底物的拓展，反应取得了 $66 \%$ 到 $94 \%$ 的 收率和 $84 \%$ 到 $98 \%$ 的对映选择性. 作者还通过 DFT 计算 方法证实了该反应是遵循异步协同作用机理的.

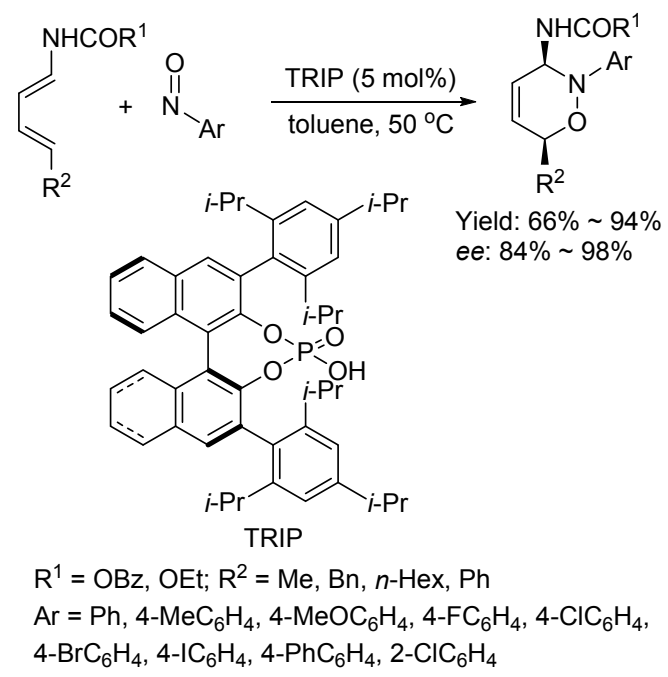

2015 年, Yamamoto 课题组 ${ }^{[34]}$ 考察了手性二膦配体 铜络合物 $\mathrm{Cu}(\mathrm{I})-\mathrm{DTBM}-\mathrm{Segphos}$ 催化作用下高活性的亚
硝基嘧啶和亚硝基哒嗪分别与环状二烯发生的不对称 分子间亚硝基 HDA 反应(Eq. 19). 对环状二烯烃底物与 亚硝基嘧啶的环加成反应考察时发现多数反应均取得 了 77\%到 99\%的收率和 9\%到 99\%的对映选择性. 对亚 硝基嘧啶环上取代基的考察发现位阻效应对收率和选 择性影响较大，当环上有大位阻取代基 $i-\operatorname{Pr}$ 时只取得了 77\%的收率和 $9 \%$ 的对映选择性，而当 4-亚硝基-2,6-二 苯基嘧啶作底物时，反应得到的产物是消旋体. 对环状 二烯烃底物与亚硝基噁嗪环加成反应的考察仅限于烯 烃底物, 多数烯烃底物均取得了优秀的收率和优秀的对 映选择性，而氮杂环二烯烃底物仅取得了 $46 \%$ 的收率. 作者利用该方法再通过 N-O 键的断裂作者成功完成了 水仙环素和石蒜西定等生物活性分子的全合成.
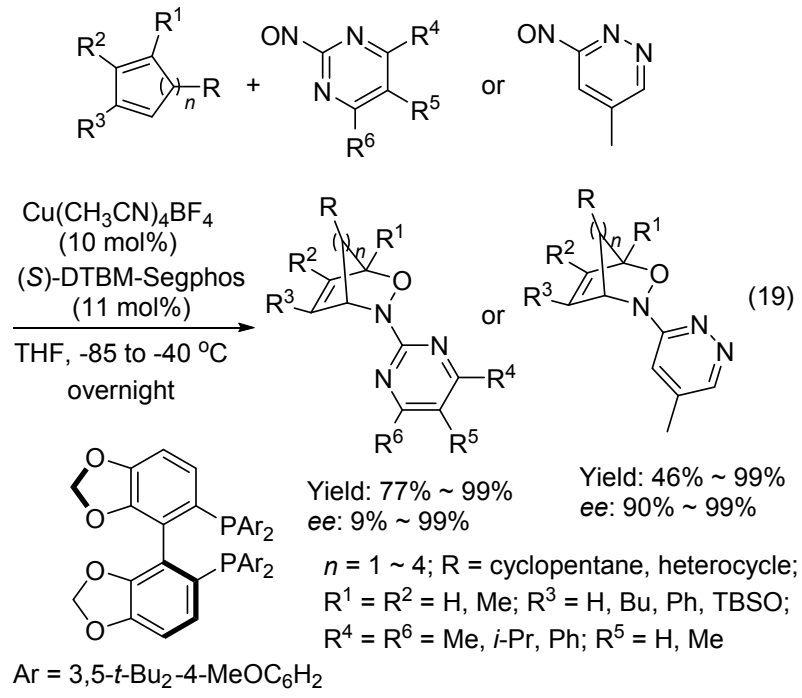

(S)-DTBM-Segphos

\section{$1.2 \mathrm{C} \equiv \mathrm{C}$ 参键参与的环加成反应}

2013 年, She 课题组 ${ }^{[35]}$ 在炔基乙醛与芳香族亚硝基 化合物环加成反应的过程中通过控制条件实现了不同 骨架异噁唑的合成(Scheme 14). 经过对条件的优化发 现以 $10 \mathrm{~mol} \% \mathrm{NHC} \mathbf{E}$ 作催化剂, $1.5 \mathrm{~mol} \cdot \mathrm{L}^{-1}$ 的 DBU 作 碱, $5 \mathrm{~mol} \cdot \mathrm{L}^{-1}$ 的 $\mathrm{CH}_{3} \mathrm{OH}$ 作添加剂, THF 作溶剂, 氩气保 护室温下反应能得到 2,5-二取代异噁唑-3(2H)-酮. 针对 对氯亚硝基苯作底物，对芳基炔醛底物拓展发现大部分 底物都能取得中等到良好的收率，而当苯环的间位和对 位带有吸电子基团 $(\mathrm{Cl})$ 时收率降低 $(\leqslant 56 \%)$, 电子效应 对邻位取代基并没有明显影响，反应都可取得较好的收 率. 呋喃、噻吩以及脂肪族炔醛也都能取得中等左右的 收率; 令人欣慰的是供电子基取代 $(p-\mathrm{Me})$ 的亚硝基苯也 能取得中等到良好的收率. 另外，作者通过优化条件确 定了合成 2,3-二取代异惡唑-5(2H)-酮环加成产物的最优 条件，以 $20 \mathrm{~mol} \%$ 的 $\mathrm{NHC} \mathbf{J}$ 作催化剂, $1.5 \mathrm{~mol} \cdot \mathrm{L}^{-1}$ 的 $\mathrm{DBU}$ 作碱, DMF 为溶剂; 通过对芳香乙炔醛底物的拓展 
表明, 大多数反应几乎不受苯环上取代基电子效应和位 阻效应的影响，都能取得中等左右的收率.

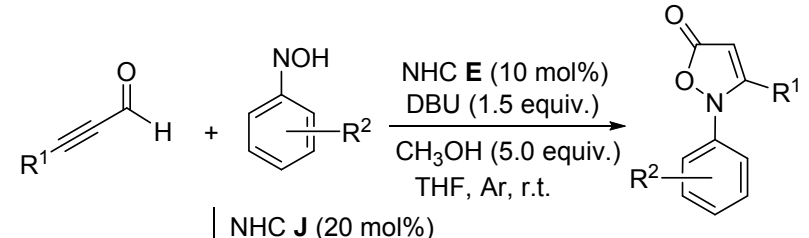
DBU (1.5 equiv.) $\quad \mathrm{R}^{1}=\mathrm{Ar}, 2$-furyl, 3-thienyl, DMF, Ar, r.t.

$\mathrm{R}^{1}$<smiles>[R]c1ccc(-n2oc(C)cc2=O)cc1</smiles>

Yield: $30 \% \sim 52 \%$

$\mathrm{R}^{1}=\mathrm{Ph}, 2-\mathrm{MeC}_{6} \mathrm{H}_{4}, 3-\mathrm{MeC}_{6} \mathrm{H}_{4}$,

4- $\mathrm{MeC}_{6} \mathrm{H}_{4}, 3-\mathrm{MeOC}_{6} \mathrm{H}_{4}$

$4-\mathrm{MeOC}_{6} \mathrm{H}_{4}, 4-\mathrm{ClC}_{6} \mathrm{H}_{4}$

$\mathrm{R}^{2}=4-\mathrm{Cl}$ alkyl; $\mathrm{R}^{2}=4-\mathrm{H}, 4-\mathrm{Me}, 4-\mathrm{Cl}$<smiles></smiles>
NHC E

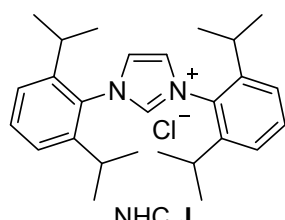

图式 $14 \mathrm{NHC}$ 催化下炔基乙醛与亚硝基苯的 $[3+2]$ 环加成反 应

Scheme 14 N-heterocyclic carbene-catalyzed [3+2] cycloadditions of alkynyl aldehydes with nitrosobenzenes

\section{3 三组分参与的环加成反应}

2010 年, Zhong 课题组 ${ }^{[36]}$ 报道了 HOTf 催化作用下 重氮醋酸酯类化合物、芳香族亚硝基化合物与烯烃的三 组份环加成反应(Eq. 20). 底物广普性的考察表明, 多数 反应均取得了高的非对映选择性和良好到优秀的收率; 在对官能团取代的亚硝基苯底物的扩展中发现, 缺电子 基取代的亚硝基苯反应效果( $\geqslant 90 \%$ yield)优于富电子取 代基取代的亚硝基苯 $(\leqslant 80 \%$ yield)，所考察的缺电子烯 烃底物取得了 $63 \%$ 到 $90 \%$ 的收率.
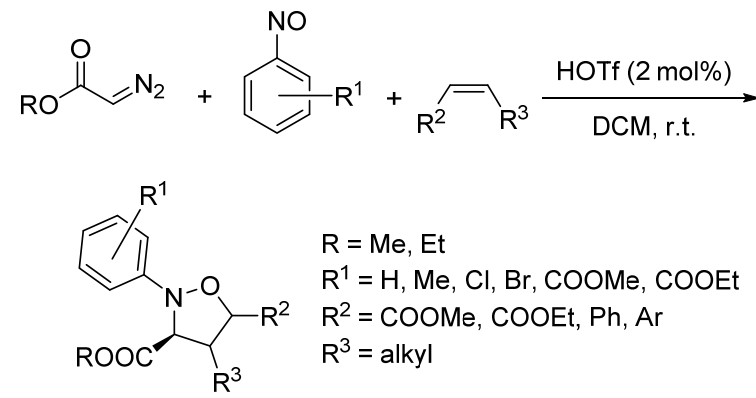

$\mathrm{R}=\mathrm{Me}, \mathrm{Et}$

$\mathrm{R}^{1}=\mathrm{H}, \mathrm{Me}, \mathrm{Cl}, \mathrm{Br}, \mathrm{COOMe}, \mathrm{COOEt}$

$\mathrm{R}^{2}=\mathrm{COOMe}, \mathrm{COOEt}, \mathrm{Ph}, \mathrm{Ar}$

Yield: $63 \% \sim 95 \%$

dr. 8:1 30:1

2012 年, Che 课题组 ${ }^{[37]}$ 报道了在 Ru 催化剂催化作 用下重氮酸酯、芳香族亚硝基化合物与烯烃的三组份环 加成反应(Eq. 21). 该反应以 $1 \mathrm{~mol} \%$ 的 $[\mathrm{Ru}(\mathrm{TTP})(\mathrm{CO})-$ $(\mathrm{MeOH})]$ 作催化剂, 二氯甲烷作溶剂, 室温条件下生成 异噁唑衍生物. 通过对各种烯烃底物的拓展表明, 大多 数产物都能取得中等到优秀的收率和良好到优秀的非

对映选择性，对亚硝基苯衍生物的扩展表明，吸电子官 能团取代的亚硝基苯和杂芳香亚硝基化合物能取得良 好到优秀的收率和优秀的非对映选择性，而给电子官能 团取代的亚硝基苯尽管能取得同样优秀的非对映选择 性，然而仅取得较差的收率，如对甲氧基取代时则只能 得到小于 $5 \%$ 的收率。

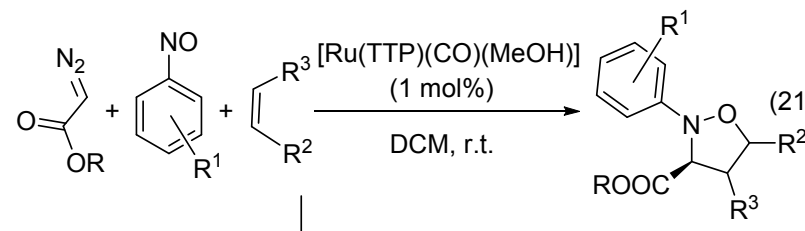

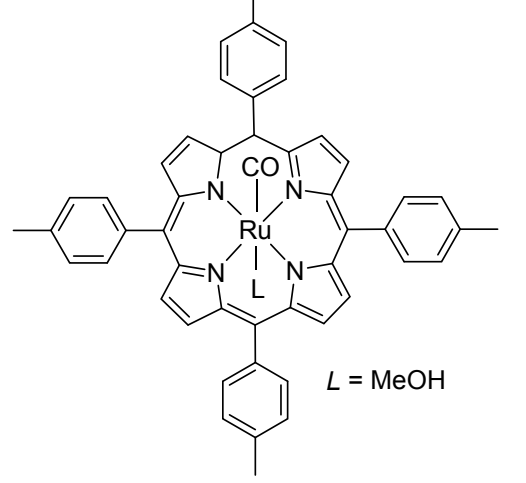

[Ru(TTP)(CO)(MeOH)]

$\mathrm{R}=\mathrm{Et}, t-\mathrm{Bu},\left(\mathrm{CH}_{2}\right)_{4} \mathrm{Ph} ; \mathrm{R}^{1}=\mathrm{H}, \mathrm{Me}, \mathrm{OMe}, \mathrm{Cl}, \mathrm{Br}, \mathrm{NO}_{2}, \mathrm{COOEt}$

$\mathrm{R}^{2}$ = COOMe, COOEt, $\mathrm{CH}_{2} \mathrm{OH}, \mathrm{CH}_{2} \mathrm{Br}, \mathrm{CH}_{2} \mathrm{NHCbzPh}, \mathrm{Ar}$;

$\mathrm{R}^{3}=$ alkyl

2013 年, Molander 课题组 ${ }^{[38]}$ 报道了三氟甲基重氮甲 烷、芳香族亚硝基化合物与烯烃在无催化剂作用下制备 异噁唑衍生物的反应(Eq. 22)。对不同烯烃的拓展表明 烯烃底物都能取得中等到优秀的收率和优秀的非对映 选择性，缺电子芳香族亚硝基化合物和杂芳香亚硝基化 合物可以取得 $71 \%$ 到 $94 \%$ 的收率。

$$
\begin{aligned}
& \mathrm{F}_{3} \mathrm{C}=\mathrm{N}_{2}+(\mathrm{Het}) \mathrm{Ar}^{-}-\mathrm{N}_{\mathrm{O}}+\mathrm{R}^{1} \stackrel{\mathrm{DCM}, 70{ }^{\circ} \mathrm{C}}{\longrightarrow} \\
& \text { Yield: } 55 \% \sim 96 \% \\
& \mathrm{R}^{1}=\mathrm{COOMe}, \mathrm{COOEt}, \mathrm{CH}_{2} \mathrm{Br}, \mathrm{Ph}^{2} \mathrm{R}^{2}=\text { alkyl; } \\
& \mathrm{Ar}=3-\mathrm{MeO}_{2} \mathrm{CC}_{6} \mathrm{H}_{4}, 3-\mathrm{CH}_{3} \mathrm{OCC}_{6} \mathrm{H}_{4}, 4-\mathrm{ClC}_{6} \mathrm{H}_{4}, 4-\mathrm{BrC}_{6} \mathrm{H}_{4}
\end{aligned}
$$

2013 年, Huang 课题组 ${ }^{[39]}$ 以芳基丙烯化合物、亚硝 基苯和 $N$-烷基化马来酰亚胺作底物，于 $50{ }^{\circ} \mathrm{C}$ 条件下， 在 $\mathrm{Cu}(\mathrm{OAc})_{2}$ 和配体 2,2-联吡定的催化作用下，合成了双 环异噁唑衍生物(Eq. 23). 反应的广普性研究表明, 所考 察底物均取得了中等的收率和良好到优秀的非对映选 择性，且反应速率不受电子效应和空间位阻效应的影 响. 研究证明 $\mathrm{N}$ 原子上连接基团 $\mathrm{R}^{2}$ 的种类对选择性有 一定的影响，烷基取代的选择性优于芳基取代的。

2014 年, Che 课题组 ${ }^{[40]}$ 又在 $\mathrm{Ru}$ 催化剂催化作用下 
<smiles></smiles><smiles>[R]c1cccc(/C=C/[C@H]2[C@H]3C(=O)N([R])C(=O)[C@@H]3ON2c2ccccc2)c1</smiles>

Yield: $46 \% \sim 66 \%$ dr. 7:1 37:2

$\mathrm{R}^{1}=$ 2-Me. 2-OTs, 4-OMe, 4-F, 4-CF 3 , 4-CN; $\mathrm{R}^{2}=\mathrm{Me}, \mathrm{Bn}, \mathrm{Ph}$

考察了重氮化合物、芳香族亚硝基化合物与炔烃的环加 成反应(Eq. 24), 该体系能制得多官能团化的氮杂环丙 烷. 控制实验的结果表明, 该体系首先生成五元环异噁 唑中间体, 随后经过分子重排生成多官能团取代的氮杂 环丙烷. 底物广普性的考察表明, 脂肪族炔烃底物均能 取得中等到优秀的收率和中等到优秀的非对映选择性, 芳香炔烃底物的拓展仅限于苯丙炔酸甲酯, 取得了 $96 \%$ 的收率; 重氮磷酸酯和重氮苯乙酮相比于重氮乙酸乙酯 有着更高的非对映选择性. 芳香族亚硝基化合物苯环上 取代基的电子效应对反应没有明显的影响，均能取得良 好到优秀的收率和优秀的非对映选择性.

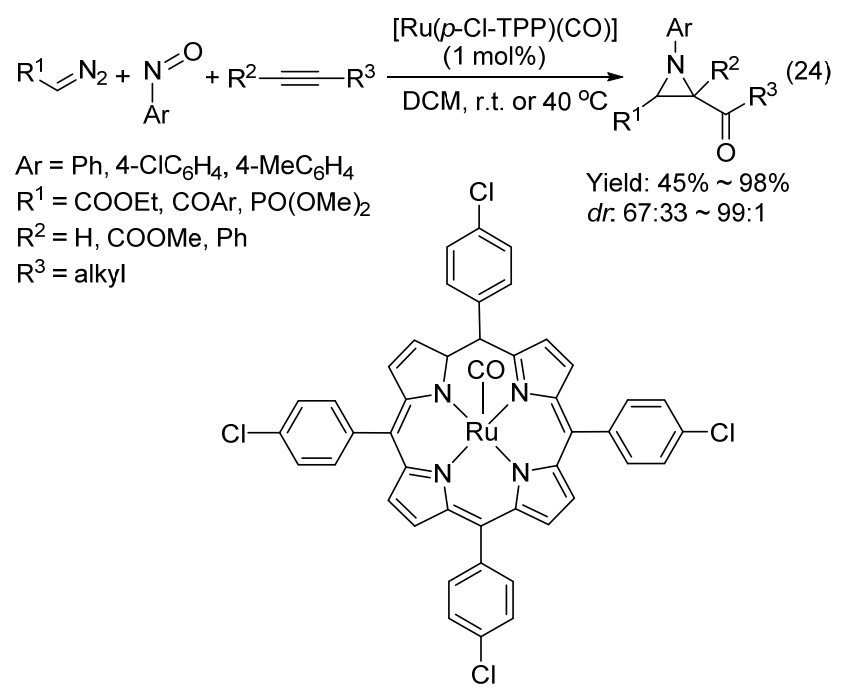

[Ru(p-Cl-TPP)(CO)]

2015 年, $\mathrm{Liu}$ 课题组 ${ }^{[41]}$ 使用 $[\mathrm{IPrAuCl}] / \mathrm{AgSbF}_{6}[\mathrm{IPr}=$ 1,3-双 (二异丙基苯基)咪唑-2-亚基]作为一种有效的催化 剂来催化重氮乙酸乙酯、芳香族亚硝基化合物与乙烯基 重氮化合物发生的三组份环加成反应(Eqs. 25, 26). 反 应的广普性考察表明，乙烯基重氮酮类底物都能取得良 好的收率 $(78 \% \sim 85 \%)$, 而乙烯基重氮羧酸酯类底物仅 取得中等左右的收率 $(63 \% \sim 79 \%)$, 富电子基和缺电子 基取代的亚硝基苯取得的收率没有明显差别. 此外, 作 者发现, 环加成产物在[IPrAuCl] $/ \mathrm{AgSbF}_{6}$ (5 mol\%)催化
作用下即可实现 $[3,3]$ 转移，几乎当量地转化成七元环产 物; 接着作者对其它异噁唑衍生物也进行了实验，均取 得了良好到优秀的收率.

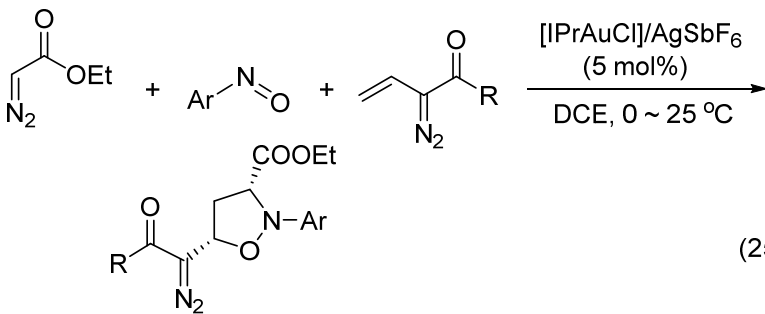

Yield: $63 \% \sim 85 \%$

$\mathrm{R}=\mathrm{OEt}$, O-t-Bu, O-n-Bu, $\mathrm{Ph}, \mathrm{Ar}$,, 3-furyl, 3-thienyl

$\mathrm{Ar}=\mathrm{Ph}, 4-\mathrm{MeC}_{6} \mathrm{H}_{4}, 4-\mathrm{ClC}_{6} \mathrm{H}_{4}, 4-\mathrm{BrC}_{6} \mathrm{H}_{4}$

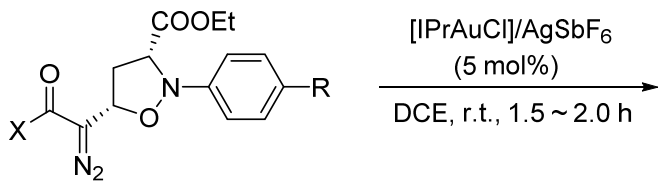<smiles>[X][R]OC(=O)C1CC(O)C(C([X])=O)c2cc([R])ccc2N1</smiles>

Yield: $76 \% \sim 94 \%$<smiles>[R][X]C1CC(=O)C(C([X])O)c2cc([R])ccc2N1</smiles>

$\mathrm{X}=\mathrm{R}^{\prime}$
$\mathrm{X}=\mathrm{OEt}$, O-t-Bu, $\mathrm{Ph}, 4-\mathrm{MeOC}_{6} \mathrm{H}_{4}$, 3-furyl, 3-thienyl; $\mathrm{R}=\mathrm{Me}, \mathrm{Cl}, \mathrm{Br}$

\section{4 环丙烷参与的环加成反应}

2014 年, Studer 课题组 ${ }^{[42]}$ 报道了取代环丙烷与芳香 族亚硝基化合物的环加成反应(Eq. 27). 通过篮选表明, 使用 $20 \mathrm{~mol} \% \mathrm{MgBr}_{2}$ 作催化剂, DCE 作溶剂, $90{ }^{\circ} \mathrm{C}$ 条件 下反应可取得最高收率. 反应广普性考察表明，含有不 同取代基的环丙烷与亚硝基苯反应来制备异噁唑衍生 物，都可得到单一异构体产物和中等到良好的收率; 当 环丙烷上的取代基 $\mathrm{R}$ 为脂肪官能团时，反应最高收率可 达到 $82 \%$; 而当 $\mathrm{R}$ 为芳香基官能团时， $\mathrm{R}$ 中苯环上有供 电子取代基时反应取得较高的收率，该反应对䒺基环丙 烷和呋喃基环丙烷也有一定的广普性，反应分别可取得 60\%和 40\%的收率. 对取代亚硝基苯底物的拓展表明， 吸电子基团取代的亚硝基苯能取得好到优秀的收率 $(\geqslant 78 \%$ ), 而供电子基( $\mathrm{Me})$ 只能取得 50\%的收率.

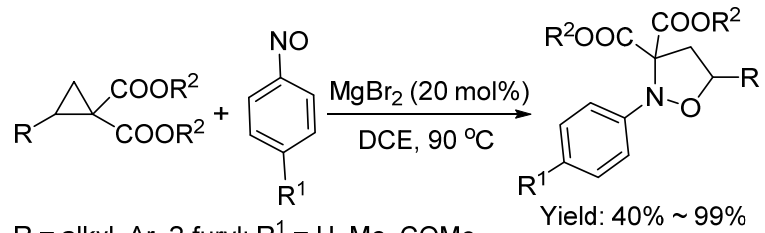

$\mathrm{R}=$ alkyl, Ar, 2-furyl; $\mathrm{R}^{1}=\mathrm{H}, \mathrm{Me}, \mathrm{COMe}$

COOEt, $\mathrm{Br}, \mathrm{OCF}_{3}, \mathrm{NO}_{2} ; \mathrm{R}^{2}=\mathrm{Me}, \mathrm{Et}, t-\mathrm{Bu}$

\section{5 环丁烷参与的环加成反应}

2014 年, Pagenkopf 课题组 ${ }^{[43]}$ 报道了在 $\mathrm{Yb}(\mathrm{OTf})_{3}$ 催 
化作用下，环丁烷与芳香族亚硝基化合物的 $[4+2]$ 环加 成反应(Eq. 28), 该反应以产物 $\mathbf{I}$ 为主. 作者对含有不同 取代基的亚硝基苯底物进行了拓展, 多数单卤代芳香亚 硝基化合物均取得了优秀的收率和优秀的区域选择性, 而 2,4-二澳亚硝基苯仅取得了 47\%的收率，当亚硝基化 合物对位有强吸电子基取代时(如 $\mathrm{CN} 、 \mathrm{COMe} 、 \mathrm{CO}_{2} \mathrm{Et}$ 和 $\mathrm{NO}_{2}$ ), 反应收率在 $60 \%$ 左右且有少量异构体生成; 富 电子的亚硝基底物收率较差, 供电子效应较强的 $\mathrm{OCH}_{3}$ 和 $\mathrm{N}\left(\mathrm{CH}_{3}\right)_{2}$ 取代的亚硝基苯未能发生反应.
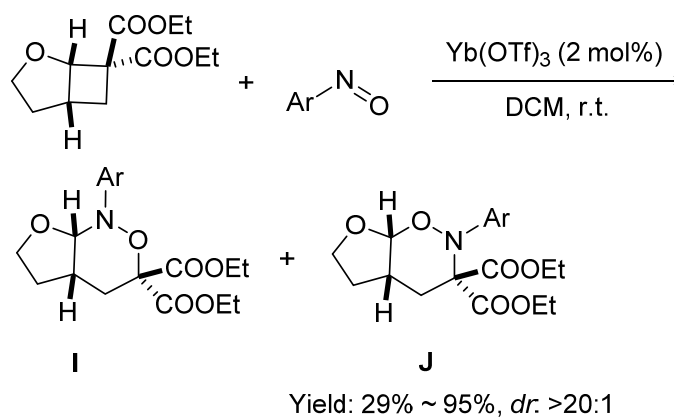

$\mathrm{Ar}=\mathrm{Ph}, 4-\mathrm{ClC}_{6} \mathrm{H}_{4}, 4-\mathrm{BrC}_{6} \mathrm{H}_{4}, 3-\mathrm{ClC}_{6} \mathrm{H}_{4}, 3-\mathrm{BrC}_{6} \mathrm{H}_{4}, 2,4-\mathrm{Cl}_{2} \mathrm{C}_{6} \mathrm{H}_{3}$, $4-\mathrm{CNC}_{6} \mathrm{H}_{4}, 6-\mathrm{O}_{2} \mathrm{NC}_{6} \mathrm{H}_{4}, 4-\mathrm{MeC}_{6} \mathrm{H}_{4}, 4-\mathrm{CH}_{3} \mathrm{OC}_{6} \mathrm{H}_{4}$

2015 年, Pagenkopf 课题组 ${ }^{[44]}$ 利用 $\mathrm{MgI}_{2}$ 作促进剂继 续考察了芳香族亚硝基化合物与环丁烷的环加成反应 (Eq. 29). 通过对路易斯酸的篮选发现 $\mathrm{MgI}_{2}$ 能有效促进 [4+2]环加成反应的顺利进行, 产物以乙缩醛异构体 $\mathbf{L}$ 为主, 这与 $\mathrm{Yb}(\mathrm{OTf})_{3}$ 催化体系的选择性截然相反. 通过 对不同亚硝基化合物的考察发现, 含有吸电子取代基的 亚硝基苯和杂环亚硝基化合物参与反应时, 产物主要以 $\mathbf{L}$ 为主，供电子基取代的亚硝基化合物产物以 $\mathbf{M}$ 为主; 然而所有反应收率普遍较差 $(19 \% \sim 56 \%)$. 作者将环加 成产物置于 $50 \mathrm{~mol} \%$ 的 $\mathrm{MgI}_{2}$ 二氯甲烷溶液中搅拌过夜 后会有吡咯烷生成.
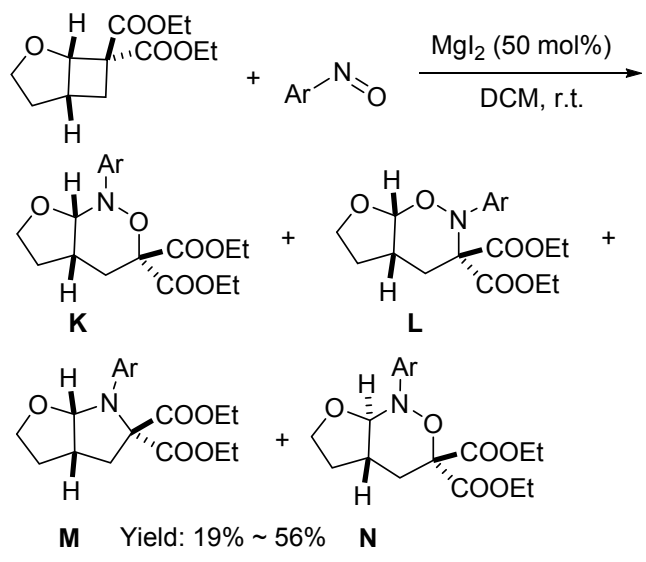

$\mathrm{Ar}=\mathrm{Ph}, 4-\mathrm{MeOC}_{6} \mathrm{H}_{4}, 4-\mathrm{CNC}_{6} \mathrm{H}_{4}$, 2-pyridine, 4-N $\left(\mathrm{CH}_{3}\right)_{2} \mathrm{C}_{6} \mathrm{H}_{4}, \mathrm{~N}$-Boc-5-nitrosoindole

\section{6 噁唑参与的环加成反应}

1998 年, Ibata 课题组 ${ }^{[45]}$ 利用噁唑与芳香族亚硝基
化合物的 $[3+2]$ 环加成反应成功合成了一系列噁二唑衍 生物(Eq. 30). 该反应在氮气保护下于乙腈中无需催化 剂即可顺利进行. 该合成方法简单高效, 大多底物均取 得单一异构体产物和中等到优秀的收率，仅二甲基和三 甲基取代的噁唑收率较低分别为 38\%和 $29 \%$ 。 反应机理 表明：选择性主要由中间体的稳定性控制，首先噁唑的 2 位或 4 位进攻亚硝基化合物, 产生两种两性离子中间 体，其中噁唑的 2 位对亚硝基化合物亲核进攻产生的硝 酮中间体比较稳定, 更容易参与反应得到目标产物.
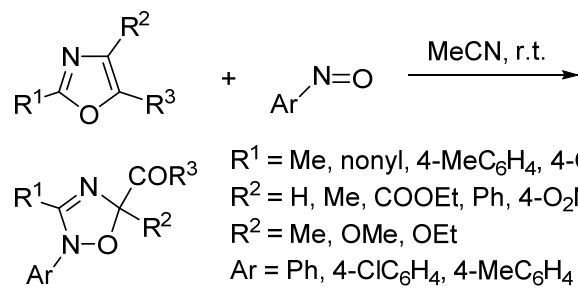

$\mathrm{R}^{1}=\mathrm{Me}$, nonyl, 4- $\mathrm{MeC}_{6} \mathrm{H}_{4}, 4-\mathrm{OMeC}_{6} \mathrm{H}_{4}$ $\mathrm{R}^{2}=\mathrm{H}, \mathrm{Me}, \mathrm{COOEt}, \mathrm{Ph}, 4-\mathrm{O}_{2} \mathrm{NC}_{6} \mathrm{H}_{4}$ $\mathrm{R}^{2}=\mathrm{Me}, \mathrm{OMe}, \mathrm{OEt}$

Yield: $29 \% \sim 100 \%$

\section{7 串联 $\alpha$-aminoxylation/aza-Michael 反应}

2008 年, Zhong 课题组 ${ }^{[46]}$ 报道了 $L$-脯氨酸催化 2-(5-氧代亚戊基)丙二酸酯与芳香族亚硝基化合物的串 联氨氧化-杂迈克反应来合成四氢-1,2-噁嗪(Eq. 31). 反 应过程首先是亚硝基化合物在酫基邻位发生氨氧化作 用，然后再与双键发生氮 aza-Michael 加成反应生成噁 嗪衍生物. 通过对不同底物的拓展，反应取得了 $63 \%$ 到 $84 \%$ 的收率，也取得了优秀的非对映选择性和对映选择 性.
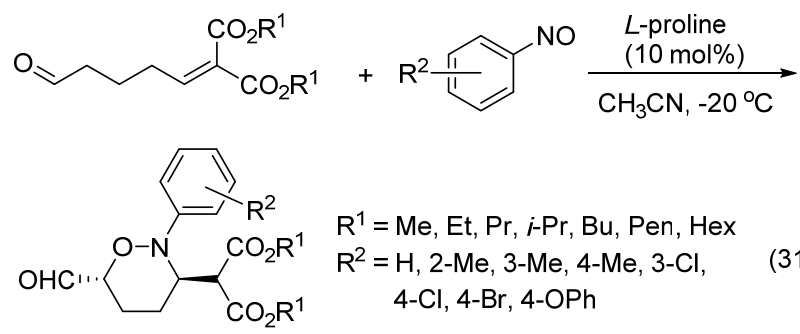

Yield: $63 \% \sim 84 \%$ ee: $92 \% \sim 99 \%, d r .>99: 1$

\section{2 乙烯基亚硝基化合物作为 3 原子组分参与的 环加成反应}

\section{$2.1 \mathrm{C}=\mathrm{N}$ 双键参与的环加成反应}

2006 年, Mahajan 课题组 ${ }^{[47]}$ 报道了 $\alpha$-亚硝基乙烯与 醛亚胺在二氯甲烷中于室温条件下发生的环加成反应 (Scheme 15). 通过对醛亚胺底物的广普性考察表明，当 $R$ 为芳基时主要发生 $[3+2]$ 环加成反应，得到具有良好 收率的五元环产物. 而当 $\mathrm{R}$ 为脂肪基团时，反应的选择 性不高, 除了得到 $[3+2]$ 环加成产物外, 还有 $[4+2]$ 环 加成产物, 且收率都不高. 


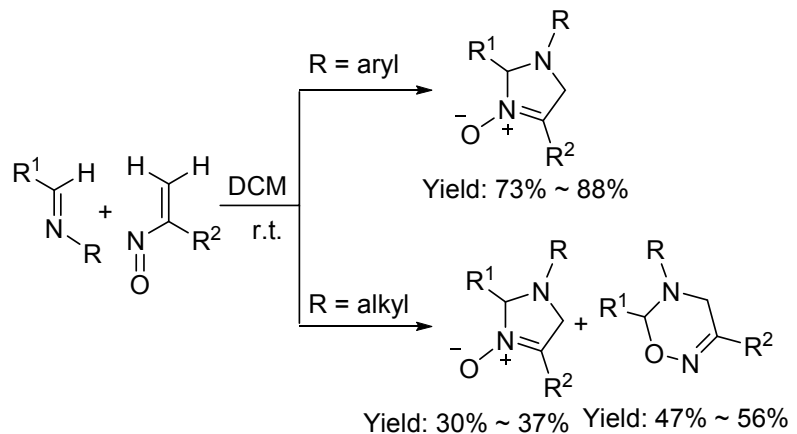

$\mathrm{R}=\mathrm{Ar}, n-\mathrm{Bu}, i-\mathrm{Pr}$, cycloalkyl, furyl, benzyl

$\mathrm{R}^{1}=\mathrm{R}^{2}=\mathrm{Ar}$

图式 15 亚硝基烯与亚胺的环加成反应

Scheme 15 Cycloaddition reactions of nitrosoalkenes with imines

\section{$2.2 \mathrm{C}=\mathrm{C}$ 双键参与的环加成反应}

2009 年, Palacios 课题组 ${ }^{[48]}$ 报道了无催化剂条件下 烯胺与亚硝基烯的 $[3+2]$ 环加成反应(Eq. 32). 通常情况 下，亚硝基烯作为 $4 \pi$ 电子共轭体系很容易与亲二烯体 发生 $[4+2]$ 环加成, 然而在该体系中都未发现六元环产 物, 作者认为磷酸酯基团的吸电子效应更有利于烯胺与 亚硝基烯烃发生 Michael 加成反应，该加成产物的关环 是发生 $[3+2]$ 环加成反应的关键步骤. 反应普适性的考 察表明, 多数底物都能得到中等到优秀的收率 $(67 \%$ 94\%).

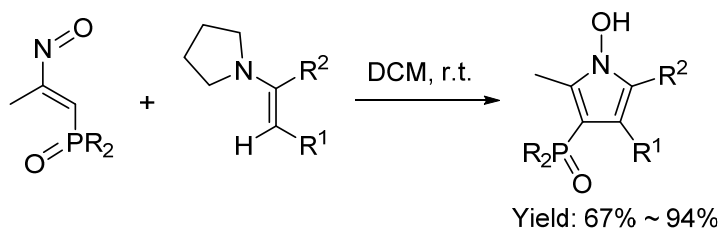

$\mathrm{R}=\mathrm{OEt}, \mathrm{Ph} ; \mathrm{R}^{1}=\mathrm{COOEt}, \mathrm{Bn}, i-\mathrm{Pr}, \mathrm{Pr}, \mathrm{Ph} ; \mathrm{R}^{2}=\mathrm{H}, \mathrm{Ph}$

2015 年, Nemes 课题组 ${ }^{[49]}$ 报道了无催化剂条件下 2-[硝基(亚硝基)亚甲基]吡咯烷与烯烃或炔烃在 DMF 中 发生的环加成反应(Eq. 33). 通过对底物的拓展发现, 产 物主要以 $\mathbf{P}$ 为主, 多数端烯烃仅能取得中等以下的收率 $(15 \% \sim 54 \%)$, 而双边取代的烯烃和环状烯烃只能取得 更低的收率 $(10 \% \sim 32 \%)$. 对不同炔烃底物的考察表明, 芳香端炔烃尽管几乎不受芳环上取代基电子效应的影 响, 但反应收率不足 $60 \%$; 而脂肪族炔烃作底物也仅能 取得与脂肪族烯烃相近的收率, 同样, 单取代的末端炔 烃也能取得优于双边取代炔烃的收率. 由该反应制备的 2-异噁唑-二氢吡咯衍生物因其特殊的环状结构有着很 重要的合成价值, 能合成众多具有药用价值的杂环化合 物.

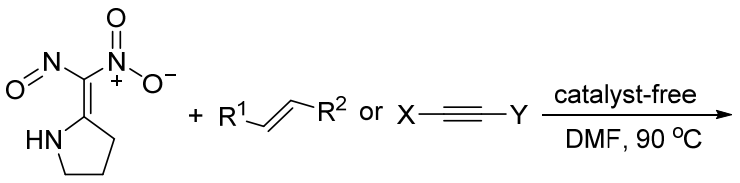<smiles>[R10]c1onc(C2=NCCC2)c1[R10]</smiles>

o<smiles>[R10]c1onc(C2=NCCC2=NO)c1[R10]</smiles>

$P$
$\mathrm{R}^{1}=\mathrm{COOH}, \mathrm{COOMe}, \mathrm{CONH}_{2}, \mathrm{COt}-\mathrm{Bu}, \mathrm{CN}, \mathrm{Ar} ; \mathrm{R}^{2}=\mathrm{H}, \mathrm{Me}$ COOMe, $\mathrm{Ph} ; \mathrm{X}=\mathrm{COOMe}, \mathrm{Ar}, \mathrm{cy}, \mathrm{CH}_{2} \mathrm{OH} ; \mathrm{Y}=\mathrm{H}, \mathrm{Me}$

\section{3 乙烯基亚硝基化合物作为 4 原子组分参与的 环加成反应}

\section{1 $\mathrm{C}=\mathrm{C}$ 双键参与的环加成反应}

2001 年, $\operatorname{Kim}$ 课题组 ${ }^{[50]}$ 报道了利用 $\alpha$ 二 二卤代芳香酮 肟在 $\mathrm{Na}_{2} \mathrm{CO}_{3}$ 作用下制备的 $\beta$-卤代亚硝基烯作为二烯体 与烯丙基化合物发生的环加成反应(Scheme 16). 使用 该反应可以很容易地制备 4 位卤代的噁嗪衍生物，相比 之前报道的两步反应得到 4 位卤代噁嗪衍生物的方法适 用性更广泛 ${ }^{[51,52]}$. 反应广普性考察表明，当 $\mathrm{R}$ 为乙氧基 时, 多数产物都能得到单一异构体产物和中等到优秀的 收率，当 $\mathrm{R}$ 为叔丁氧基时，多数产物都取得了中等到优 秀的收率和中等的非对映选择性; 而当 $\mathrm{R}$ 为三甲基硅基 时，产物收率大幅度降低，仅在 $25 \%$ 左右，但非对映选 择性相比叔丁氧基取代的烯烃底物有所提高(90：1 $99: 1)$.

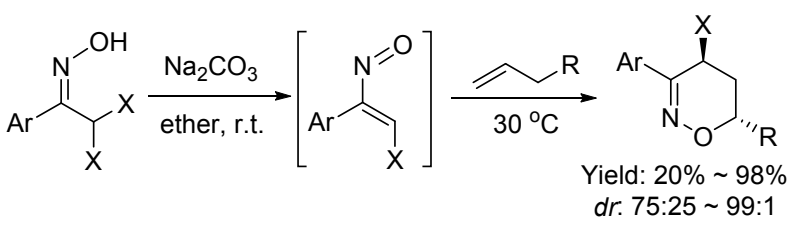

$\mathrm{X}=\mathrm{Cl}, \mathrm{Br} ; \mathrm{R}=\mathrm{OEt}, \mathrm{OBu}-\mathrm{t}, \mathrm{SiMe}_{3} ; \mathrm{Ar}=\mathrm{Ph}, 4-\mathrm{FC}_{6} \mathrm{H}_{4}, 4-\mathrm{ClC}_{6} \mathrm{H}_{4}$, 4- $\mathrm{BrC}_{6} \mathrm{H}_{4}, 4-\mathrm{NO}_{2} \mathrm{C}_{6} \mathrm{H}_{4}, 4-\mathrm{MeC}_{6} \mathrm{H}_{4}$, 2-naphthyl

图式 16 亚硝基乙烯参与的杂 DA 反应

Scheme 16 Hetero-Diels-Alder reactions nitrosoethylenes

2014 年, Palacios 课题组 ${ }^{[53]}$ 报道了 $\alpha$-卤代酮肟经 $\mathrm{NaHCO}_{3}$ 作用生成 $\alpha, \beta$-不饱和的亚硝基化合物中间体作 为二烯体与烯烃在水相中发生的环加成反应(Scheme 17). 作者考察了中间体膦酰基亚硝基二烯体与烯烃分 别在无溶剂、有机溶剂或水作溶剂条件下的环加成反应 情况. 在无溶剂条件下, 多数底物均取得了中等到良好 的收率和中等到优秀的对映选择性，而且加成产物 C-3 位为苯基时, 噁嗪产物可以发生亚胺一烯胺互变. 在有 
溶剂条件下, 多数底物均取得了良好到优秀的收率和良 好到优秀的对映选择性, 相比无溶剂体系, 有着更优秀 的收率和选择性, 从热力学稳定性考虑, 产物 $\mathbf{R}$ 相对于 产物 $\mathbf{Q}$ 更稳定.
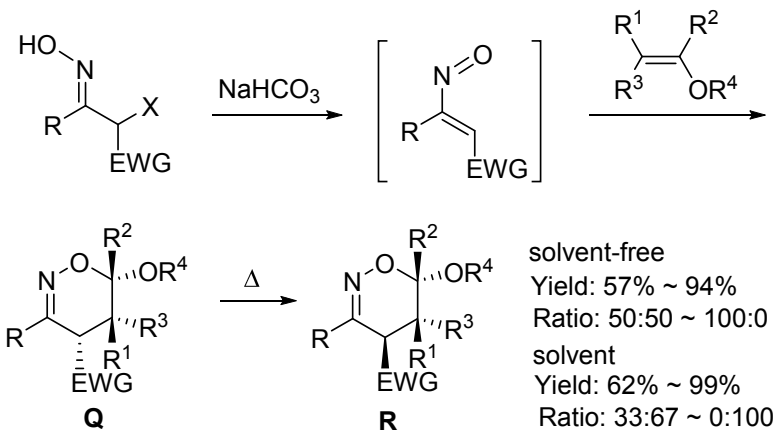

EWG $=\mathrm{P}(\mathrm{O}) \mathrm{Ph}_{2}, \mathrm{P}(\mathrm{O}) \mathrm{Et}_{2}, \mathrm{COOEt} ; \mathrm{R}=\mathrm{Me}, \mathrm{Et}, \mathrm{COOEt}, \mathrm{Ph}$;

$\mathrm{X}=\mathrm{Cl}, \mathrm{Br} ; \mathrm{R}^{1}=\mathrm{H}, i-\mathrm{Pr} ; \mathrm{R}^{2}=\mathrm{R}^{3}=\mathrm{H} ; \mathrm{R}^{1} \mathrm{R}^{2}=\left(\mathrm{CH}_{2}\right)_{3} ; \mathrm{R}^{4}=\mathrm{Me}$,

$\mathrm{SiMe}_{3} ; \mathrm{R}^{3} \mathrm{R}^{4}=\left(\mathrm{CH}_{2}\right)_{2},\left(\mathrm{CH}_{2}\right)_{3}$

图式 17 亚硝基乙烯与烯基醚类化合物的杂 DA 反应

Scheme 17 Hetero-Diels-Alder reactions of nitroso alkenes with enol ethers

\section{2 取代乙醛参与的环加成反应}

2004 年, Jørgensen 课题组 ${ }^{[54]}$ 报道了 $\alpha$-卤代酮肜与醛 发生的反电子需求 HDA 反应(Eq. 34). 该体系以 10 mol\%的吡咯烷作催化剂, 2 equiv. $\mathrm{NaOAc} \cdot 3 \mathrm{H}_{2} \mathrm{O}$ 作添加 剂, 在二氯甲烷溶剂中于室温条件下进行; 反应通过吡 咯烷与醛结合产生的烯胺与由卤代肜原位生成的亚硝 基烯烃发生 $[4+2]$ 环加成反应。反应广普性考察表明, 多数底物均取得了中等到良好的收率, 而当乙醛 $\alpha$ 位有 两个取代基时，例如异丁醛和 2,2-二苯基乙醛，则反应 未得到噁嗪产物, 可能是由于增加的位阻效应和中间体 烯胺活性的降低所致; 另外, 富电子甲氧基取代的 $\alpha$-卤 代苯乙酮肟活性明显低于吸电子硝基取代的 $\alpha$-卤代苯 乙酮肟。

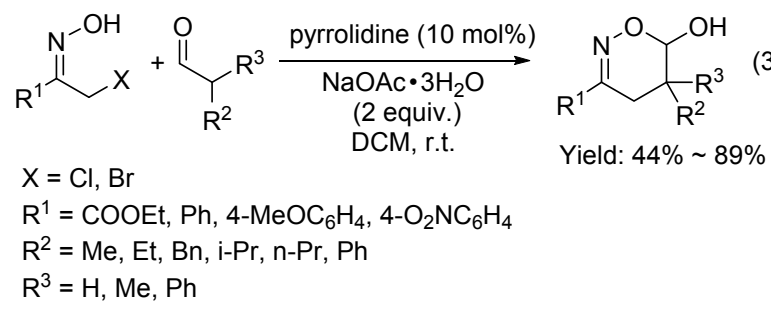

\section{4 芳基亚硝基化合物作为 3 原子组分参与的环 加成反应}

\section{1 $C \equiv C$ 参键参与的环加成反应}

2002 年, Nicholas 课题组 ${ }^{[55]}$ 用芳香族亚硝基化合物 与炔作原料报道了两种合成多官能团取代吲哚的新方
法(Scheme 18). 一种是以 $\mathrm{CO}$ 作还原剂, 在 $[\mathrm{Cp} * \mathrm{Ru}-$ $\left.(\mathrm{CO})_{2}\right]_{2}\left(\mathrm{Cp}^{*}=\mathrm{C}_{5} \mathrm{Me}_{5}\right)$ 催化作用下，芳香亚硝基化合物 与炔烃发生环加成反应制备吲哚衍生物. 通过对不同底 物的拓展，无论亚硝基苯还是给电子基取代的亚硝基苯 与苯乙炔反应都能取得中等的收率，而与双边取代的炔 烃反应收率明显下降 $(<32 \%)$. 另一种是采用两步法. 首先, 反应不需要催化剂, 在高温下即可得到加成产物 $N$-着基吲哚，接着该加成产物经过钯/碳还原即可得到 吲哚衍生物. 对该体系广普性考察表明，亚硝基芳香化 合物芳环上取代基的电子效应对反应没有明显的影响, 所考察的 10 个底物仅能取得 $29 \%$ 到 $62 \%$ 的收率.

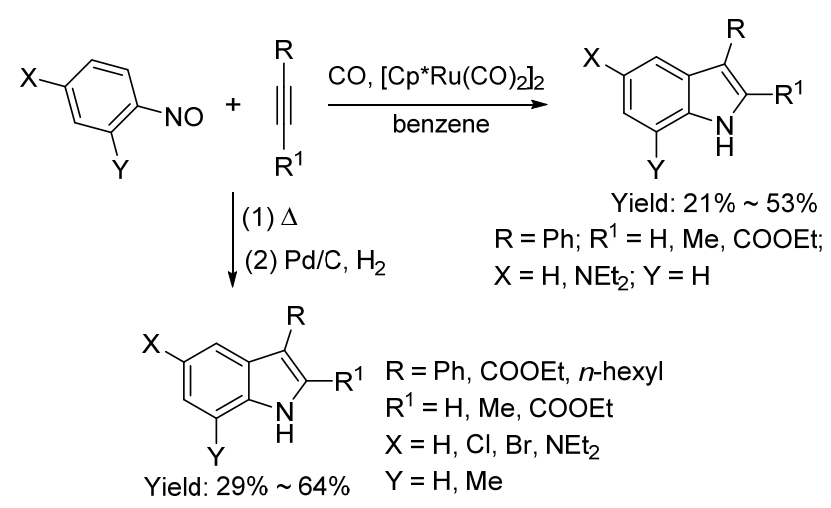

图式 18 亚硝基芳香化合物与芳香炔的环加成反应 Scheme 18 Cycloadditions of nitrosoaromatics with alkynes

2006 年, Nicholas 课题组 ${ }^{[56]}$ 报道了以 $\left(\mathrm{CH}_{3}\right)_{2} \mathrm{SO}_{4}$ 作烷 基化试剂，在碱性条件下，芳香族亚硝基化合物与末端 炔发生环加成反应制备 $N$-甲氧基吲哚衍生物的反应 (Eq. 35). 对亚硝基芳香化合物的广普性考察表明大部 分底物都能取得中等到良好的收率; 当亚硝基芳香环对 位为强吸电子基团硝基时，反应能得到当量的收率.
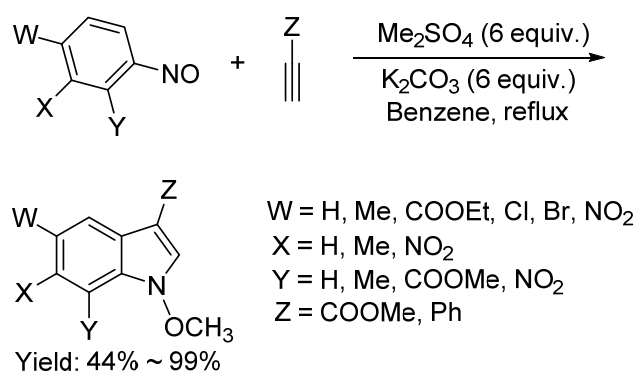

2010 年, Penoni 课题组 ${ }^{[57]}$ 以 2-氯-4-乙炔基嘧啶和芳 香族亚硝基化合物作原料，在甲苯中于 $80{ }^{\circ} \mathrm{C}$ 条件下成 功制备了具有生物活性的嘧啶取代的吲哚(Eq. 36). 作 者对不同亚硝基苯底物进行了拓展，多数底物只能得到 中等及以下的反应收率(19\% 71\%); 当亚硝基对位有 吸电子基团取代时，或者邻位有供电子基团取代时，收 率较高 $(55 \% \sim 74 \%)$. 此外，作者以 2-氨基-4-乙炔基嘧 
啶作原料, 同样条件下与芳香族亚硝基化合物反应合成 了另一种生物活性分子，收率均在 $50 \%$ 左右.

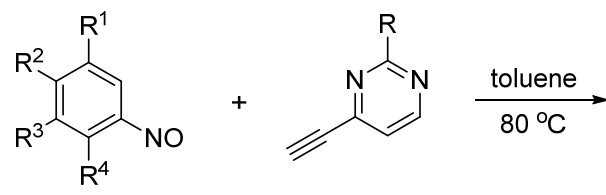<smiles>[R]c1nccc(-c2c[nH]c3c([R])c([R])c([R])c([R])c23)n1</smiles>

$\mathrm{R}=\mathrm{Cl}, \mathrm{NH}_{2} ; \mathrm{R}^{1}=\mathrm{H}, \mathrm{Br}$

$\mathrm{R}^{2}=\mathrm{H}, \mathrm{Br}, \mathrm{OCH}_{3}, \mathrm{COOH}, \mathrm{CN}, \mathrm{NO}_{2}$

$\mathrm{R}^{3}=\mathrm{H}, \mathrm{Br} ; \mathrm{R}^{4}=\mathrm{N}, \mathrm{Me}, \mathrm{CF}_{3}, \mathrm{NO}_{2}$

Yield: $19 \% \sim 71 \%$

2010 年, Srivastava 课题组 ${ }^{[58]}$ 报道了以 $\mathrm{AuCl}$ 作催化 剂, $\mathrm{NaBH}_{4}$ 作还原剂, 甲苯作溶剂, $90{ }^{\circ} \mathrm{C}$ 条件下, 芳香 族亚硝基化合物与炔烃类化合物合成 3-芳基吲哚衍生 物的反应(Eq. 37). 通过对不同底物的拓展表明, 多数底 物均取得了中等左右的收率, 双边取代的炔烃收率稍有 降低(36\% 48\%), 低活性的二乙基氨基亚硝基苯也取得 了 $42 \%$ 的收率. 最后, 作者对反应历程做了推测：第一 步先通过亚硝基化合物与炔烃的环化反应生成 $N$-羊基3-苯基吲哚, 第二步在 $\mathrm{AuCl} / \mathrm{NaBH}_{4}$ 催化还原下得到 3芳基吲哚衍生物.
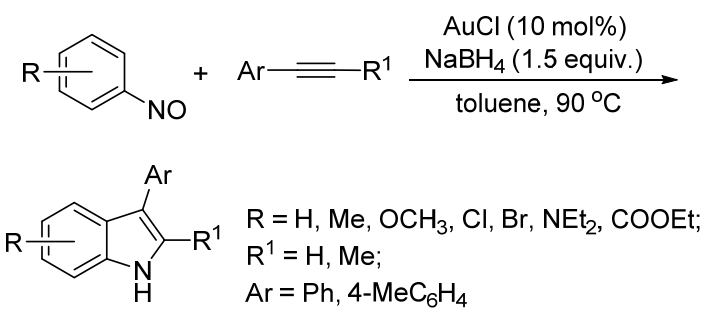

Yield: $36 \% \sim 67 \%$

2011 年, Srivastava 课题组 ${ }^{[59]}$ 报道了 $20 \mathrm{~mol} \%$ $\mathrm{CuCl}_{2} \cdot 2 \mathrm{H}_{2} \mathrm{O}$ 催化作用下芳基乙炔和芳香族亚硝基化合 物的反应(Eq. 38). 对亚硝基底物进行扩展发现, 芳香族 亚硝基化合物苯环上有吸电子取代基时，反应效果优于 苯环上有供电子取代基, 苯环上取代基的位置对反应也 有一定的影响，邻位取代基收率较低(47\% 58\%); 多 数反应都可取得中等左右的收率. 对炔烃底物广普性的 考察表明芳香端炔底物均能取得中等左右的收率而双 边取代的芳基乙炔的收率普遍较低( $<5 \% \sim 58 \%)$, 其中 二苯基乙炔几乎不反应，仅取得 $<5 \%$ 的收率.

\section{2 重氮酸酯参与的环加成反应}

2011 年, $\mathrm{Liu}$ 课题组 ${ }^{[60]}$ 又以 $5 \mathrm{~mol} \% \mathrm{P}(t-\mathrm{Bu})_{2}(o-b i-$ phenyl)AuCl/AgNTf 2 作催化剂体系 ${ }^{[9]}, \mathrm{DCE}$ 作溶剂, $25^{\circ} \mathrm{C}$ 条件下实现了烯基重氮酸酯与芳香族亚硝基化合物的 环加成反应(Eq. 39). 反应的广普性考察表明, 多数底物
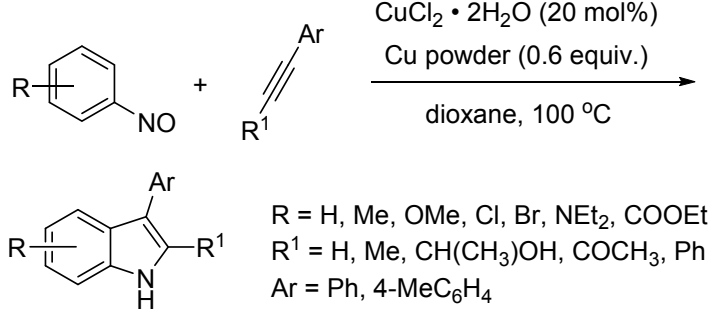

Yield: $5 \% \sim 71 \%$

均取得了 $70 \%$ 左右的收率，当 $\mathrm{R}^{2}$ 为杂环时取得了 $60 \%$ 左右的收率. 而当 $\mathrm{R}^{1}$ 为氯和甲氧基产物收率分别为 58\%和 51\%. 对芳香族亚硝基化合物的考察表明，无论 富电子基还是缺电子基取代的亚硝基苯均取得了中等 到良好的收率，其中对乙酰基亚硝基苯取得最高收率为 $82 \%$.
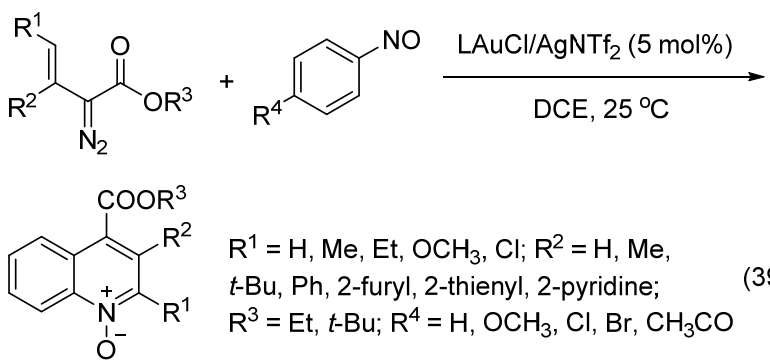

$\mathrm{R}^{1}=\mathrm{H}, \mathrm{Me}, \mathrm{Et}, \mathrm{OCH}_{3}, \mathrm{Cl} ; \mathrm{R}^{2}=\mathrm{H}, \mathrm{Me}$, $t$-Bu, $\mathrm{Ph}, 2$-furyl, 2-thienyl, 2-pyridine;

Yield: $51 \% \sim 82 \%$

\section{5 芳基亚硝基化合物作为 4 原子组分参与的环 加成反应}

2014 年, Ellman 课题组 ${ }^{[61]}$ 报道了在 $\mathrm{BF}_{3} \cdot \mathrm{EtO}_{2}$ 的催化 作用下，乙醛酸酯与芳香族亚硝基化合物生成苯并异啞 唑的反应(Eq. 40). 反应的广普性考察表明，所考察底物 取得了 $32 \%$ 到 $84 \%$ 的收率，且多数底物都得到了单一异 构体产物; 对芳香族亚硝基底物苯环上取代基位置的考 察表明，间位取代基对区域选择性影响较大，多数间位 取代的亚硝基底物得到了两种异构体，且选择性不高; 而不含取代基和对位含有取代基的亚硝基苯均得到了 单一产物. 对醛的底物拓展时发现, 亲电性较差的苯甲 醛不适用于此反应.

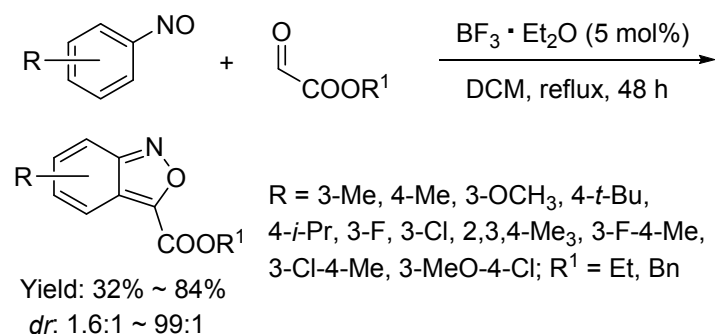

\section{6 结论与展望}

亚硝基化合物已经被广泛应用于环加成反应中来 
合成多种具有生物活性的化合物. 尽管取得了一些成 就，但由于亚硝基化合物自身的高活性，发展高化学选 择性、高区域选择性和高对映选择性的亚硝基环加成反 应仍然面临着较大的挑战. 同时，对其加成产物的进一 步应用, 也有着较大的发展空间. 因此发展高催化活性 和高选择性的催化体系, 构建温和的反应条件, 控制副 产物的产生, 丰富环加成反应的类型仍然是关于亚硝基 化合物环加成反应研究的重点课题.

\section{References}

[1] (a) Wang, W.; Lu, X. H.; Dong, X. C.; Zhao, W. L. Chin. J. Org. Chem. 2015, 35, 137 (in Chinese).

(王雯, 陆秀宏, 董肖椿, 赵伟利, 有机化学, 2015, 35, 137.)

(b) Wu, Y. Q.; Yu, L. Y.; Zhang, Q.; Li, L. D. Chin. J. Org. Chem. 2015, 35, 724 (in Chinese).

(吴玉芹, 于凉云, 张奇, 李立冬, 有机化学, 2015, 35, 724.)

(c) Zheng, J. F.; Xie, Z. Q.; Chen, X. J.; Huang, P. Q. Acta Chim. Sinica 2015, 73, 705.

(d) Cheng, G.; Yang, D. Q. Chin. J. Org. Chem. 2015, 35, 2023 (in Chinese).

(程果, 杨定乔, 有机化学, 2015, 35, 2023.)

(e) Li, G. D.; Hu, H. Y.; Kan, Y. H.; Ma, K. R. Chin. J. Org. Chem. 2014, 34, 903 (in Chinese).

(李国栋, 胡华友, 墽玉和, 马奎蓉, 有机化学, 2014, 34, 903.)

(f) Li, Q. H.; Huang, R.; Wang, C. J. Acta Chim. Sinica 2014, 72, 830 (in Chinese).

(李清华, 黄蓉, 王春江, 化学学报, 2014, 72,830.)

(g) Sun, L. H.; Liang, Z. Q.; Ye, S. Acta Chim. Sinica 2014, 72, 841 (in Chinese).

(孙利辉, 梁志钦, 叶松, 化学学报, 2014, 72, 841.)

(h) Xie, M. S.; Wu, X. X.; Wang, G.; Lin, L. L.; Feng, X. M. Acta Chim. Sinica 2014, 72, 856 (in Chinese).

(谢明胜, 武晓霞, 王刚, 林丽丽, 冯小明, 化学学报, 2014, 72, 856.)

(i) Zhou, R.; Xiao, W.; Yin, X.; Zhan, G.; Chen, Y. C. Acta Chim. Sinica 2014, 72, 862 (in Chinese).

(周容, 肖微, 尹祥, 詹固, 陈应春, 化学学报, 2014, 72, 862.)

(j) Yang, L. J.; Ma, J. A. Acta Chim. Sinica 2016, 74, 130 (in Chinese).

(杨丽军, 马军安, 化学学报, 2016, 74, 130.)

[2] Dochnahl, M.; Fu, G. C. Angew. Chem. Int. Ed. 2009, 48, 2391.

[3] Wang, T.; Huang, X. L.; Ye, S. Org. Biomol. Chem. 2010, 8, 5007.

[4] Chatterjee, I.; Jana, C. K.; Steinmetz, M.; Grimme, S.; Studer, A. Adv. Synth. Catal. 2010, 352, 945.

[5] Kang, J. Y.; Bugarin, A.; Connell, B. T. Chem. Commun. 2008, 3522.

[6] Yang, L.; Tan, B.; Wang, F.; Zhong, G. J. Org. Chem. 2009, 74, 1744.

[7] Chatterjee, I.; Fröhlich, R.; Studer, A. Angew. Chem., Int. Ed. 2011, $50,11257$.

[8] Chen, C. H.; Tsai, Y. C.; Liu, R. S. Angew. Chem., Int. Ed. 2013, 52,4599 .

[9] Zhan, M.; Zhang, S.; Huang, Z.; Xi, Z. Chem. Asian J. 2015, 10, 862.

[10] Liu, R. S.; Ghorpade, S. M.; Jadhav, P. D. Chem. Eur. J. 2016, 22, 1

[11] Arribas, C.; Carreño, M. C.; García-Ruano, J. L.; Rodríguez, J. F.; Santos, M.; Sanz-Tejedor, M. A. Org. Lett. 2000, 2, 3165.

[12] Miller, C. A; Batey, R. A. Org. Lett. 2004, 6, 699.
[13] Yamamoto, Y.; Yamamoto, H. J. Am. Chem. Soc. 2004, 126, 4128.

[14] Calvet, G.; Guillot, R.; Blanchard, N.; Kouklovsky, C. Org. Biomol. Chem. 2005, 3, 4395.

[15] Yamamoto, Y.; Yamamoto, H. Angew. Chem., Int. Ed. 2005, 44, 7082.

[16] Jana, C. K.; Studer, A. Angew. Chem., Int. Ed. 2007, 46, 6542.

[17] Jana, C. K.; Grimme, S.; Studer, A. Chem. Eur. J. 2009, 15, 9078.

[18] Monbaliu, J. C.; Marchand-Brynaert, J. Tetrahedron Lett. 2008, 49, 1839.

[19] Jana, C. K.; Studer, A. Chem. Eur. J. 2008, 14, 6326.

[20] Yang, B.; Miller, P. A.; Möllmann, U.; Miller, M. J. Org. Lett. 2009, $11,2828$.

[21] Monbaliu, J. C.; Tinant, B.; Marchand-Brynaert, J. J. Org. Chem. 2010, 75, 5478.

[22] Monbaliu, J. C. M.; Cukalovic, A.; Marchand-Brynaert, J.; Stevens, C. V. Tetrahedron Lett. 2010, 51, 5830.

[23] Yang, B.; Zöllner, T.; Gebhardt, P.; Möllmann, U.; Miller, M. J. Org. Biomol. Chem. 2010, 8, 691.

[24] Chaiyaveij, D.; Cleary, L.; Batsanov, A. S.; Marder, T. B.; Shea, K. J.; Whiting, A. Org. Lett. 2011, 13, 3442.

[25] Jenkins, N. E.; Ware Jr, R. W.; Atkinson, R. N.; King, S. B. Synth. Commun. 2000, 30, 947.

[26] Flower, K. R.; Lightfoot, A. P.; Wan, H.; Whiting, A. J. Chem. Soc., Perkin Trans. 1 2002, 18, 2058.

[27] Frazier, C. P.; Bugarin, A.; Engelking, J. R.; Read de Alaniz, J. Org. Lett. 2012, 14, 3620.

[28] Anand, A.; Bhargava, G.; Singh, P.; Mehra, S.; Kumar, V.; Mahajan, M. P.; Bisetty, K. Lett. Org. Chem. 2012, 9, 411.

[29] Berti, F.; Di Bussolo, V.; Pineschi, M. J. Org. Chem. 2013, 78, 7324.

[30] Samoshin, A. V.; Hawker, C. J.; Read de Alaniz, J. ACS Macro Lett. 2014, 3, 753

[31] Eberlin, L.; Carboni, B.; Whiting, A. J. Org. Chem. 2015, 80, 6574.

[32] Chaiyaveij, D.; Batsanov, A. S.; Fox, M. A.; Marder, T. B.; Whiting, A. J. Org. Chem. 2015, 80, 9518.

[33] Pous, J.; Courant, T.; Bernadat, G.; Iorga, B. I.; Blanchard, F.; Masson, G. J. Am. Chem. Soc. 2015, 137, 11950.

[34] Maji, B.; Yamamoto, H. J. Am. Chem. Soc. 2015, 137, 15957.

[35] Han, R.; Qi, J.; Gu, J.; Ma, D.; Xie, X.; She, X. ACS Catal. 2013, 3, 2705.

[36] Xu, Z. J.; Zhu, D.; Zeng, X.; Wang, F.; Tan, B.; Hou, Y.; Lv, Y.; Zhong, G. Chem. Commun. 2010, 46, 2504.

[37] Reddy, A. R.; Guo, Z.; Siu, F. M.; Lok, C. N.; Liu, F.; Yeung, K. C.; Zhou, C. Y.; Che, C. M. Org. Biomol. Chem. 2012, 10, 9165.

[38] Molander, G. A.; Cavalcanti, L. N. Org. Lett. 2013, 15, 3166.

[39] Chen, H.; Wang, Z.; Zhang, Y.; Huang, Y. J. Org. Chem. 2013, 78, 3503.

[40] Reddy, A. R.; Zhou, C. Y.; Che, C. M. Org. Lett. 2014, 16, 1048.

[41] Pagar, V. V.; Liu, R. S. Angew. Chem., Int. Ed. 2015, 54, 4923.

[42] Chakrabarty, S.; Chatterjee, I.; Wibbeling, B.; Daniliuc, C. G.; Studer, A. Angew. Chem., Int. Ed. 2014, 53, 5964.

[43] Vemula, N., Stevens, A. C.; Schon, T. B.; Pagenkopf, B. L. Chem. Commun. 2014, 50, 1668.

[44] Vemula, N.; Pagenkopf, B. L. Eur. J. Org. Chem. 2015, 4900.

[45] Suga, H.; Shi, X. L.; Ibata, T. Bull. Chem. Soc. Jpn. 1998, 71, 1231.

[46] Zhu, D.; Lu, M.; Chua, P. J.; Tan, B.; Wang, F.; Yang, X.; Zhong, G. Org. Lett. 2008, 10, 4585.

[47] Marwaha, A.; Singh, P.; Mahajan, M. P. Tetrahedron 2006, 62, 5474.

[48] de los Santos, J. M.; Ignacio, R.; Aparicio, D.; Palacios, F.; Ezpeleta, J. M. J. Org. Chem. 2009, 74, 3444.

[49] Kondacs, L. A.; Pilipecz, M. V.; Mucsi, Z.; Balázs, B.; Gáti, T.; 
Nyerges, M.; Dancsó, A.; Nemes, P. Eur. J. Org. Chem. 2015, 6872.

[50] Yoon, S. C.; Kim, K. J.; Park, Y. J. J. Org. Chem. 2001, 66, 7334.

[51] Shatzmiller, S.; Lidor, R.; Bahar, E.; Goldberg, I. Lebigs Ann. Chem. 1991, 851.

[52] Paulini, K.; Reißig, H. U. Chem. Ber. 1994, 127, 685.

[53] de los Santos, J. M.; Ignacio, R.; Es Sbai, Z.; Aparicio, D.; Palacios, F. J. Org. Chem. 2014, 79, 7607.

[54] Wabnitz, T. C.; Saaby, S.; Jørgensen, K. A. Org. Biomol. Chem. 2004, 2, 828 .

[55] Penoni, A.; Volkmann, J.; Nicholas, K. M. Org. Lett. 2002, 4, 699.

[56] Penoni, A.; Palmisano, G.; Broggini, G.; Kadowaki, A.; Nicholas,
K. M. J. Org. Chem. 2006, 71, 823.

[57] Tibiletti, F.; Simonetti, M.; Nicholas, K. M.; Palmisano, G.; Parravicini, M.; Imbesi, F.; Tollari, S.; Penoni, A. Tetrahedron 2010, 66, 1280.

[58] Murru, S.; Gallo, A. A.; Srivastava, R. S. ACS Catal. 2010, 1, 29.

[59] Murru, S.; Gallo, A. A.; Srivastava, R. S. Eur. J. Org. Chem. 2011, 2035.

[60] Pagar, V. V.; Jadhav, A. M.; Liu, R. S. J. Am. Chem. Soc. 2011, 133, 20728.

Otley, K. D.; Ellman, J. A. J. Org. Chem. 2014, 79, 8296.

(Li, L.; Fan, Y.) 